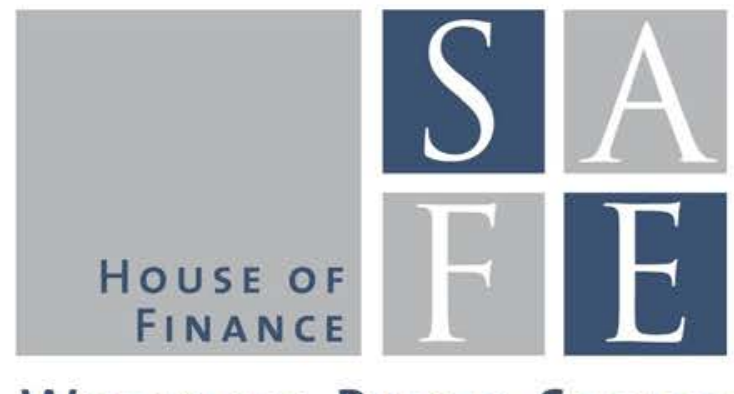

WORKING PAPER SERIES

Eren Gürer - Alfons J. Weichenrieder

\title{
Pro-rich Inflation in Europe: Implications for the Measurement of Inequality
}

SAFE Working Paper No. 209

SAFE I Sustainable Architecture for Finance in Europe A cooperation of the Center for Financial Studies and Goethe University Frankfurt 


\section{Non-Technical Summary}

The development of inequality has received increasing attention in recent years. While inequality of disposable income has significantly increased in some countries, it was rather stable in other European countries.

One possible weakness of existing studies that try to document the development of inequality is the use of a uniform consumer price inflation rate (CPI). Using such a common CPI implicitly assumes that the consumption baskets of low income households are subject to the same price increase as the consumption baskets of more affluent households. However, if price increases are more prevalent for goods that are disproportionally consumed by poorer households, then the standard approach of studying inequality measures over time will underestimate the change in inequality.

Against this background, the present paper studies the distributional consequences of a systematic variation in expenditure shares and prices. Using European Union Household Budget Surveys and Harmonized Index of Consumer Prices data, we construct householdspecific price indices and ask whether inflation in recent years was lower for households belonging to upper deciles.

Within a sample of 25 EU countries over the period 2001-15, our calculations reveal the existence of a pro-rich inflation. This means that, compared to consumption baskets consumed by lower deciles, the consumption baskets of the more affluent deciles had a lower inflation rate. This holds for almost all countries.

Across countries, the consumption bundles of the poorest deciles have, on average, become 10.5 percentage points more expensive than those of the richest decile. This translates in a yearly inflation difference of 0.72 percentage points and is a considerable difference if compared to the average CPI of $2.67 \%$.

We find that ignoring the differential inflation across the distribution underestimates the change in the Gini measure (based on consumption expenditure) by up to 0.03 points.

The inflation effect is not uniform across countries. Therefore, the cross-country heterogeneity of pro-rich inflation is large enough to alter the inequality ranking of numerous countries. The average inflation effect we detect is almost as large as the change in the standard Gini measure over the period of interest.

For many countries, the usual inequality measures do not indicate a pronounced change. Our results may help explaining the general concern among Europeans about increasing inequality that nevertheless seems to exist.

Our study raises the question of how governments should react with their income redistribution to different inflation rates for differently affluent households. 


\title{
Pro-rich Inflation in Europe: Implications for the Measurement of Inequality
}

by

\author{
Eren Gürer
}

(Goethe University Frankfurt)

and

\begin{abstract}
Alfons J. Weichenrieder\#
(Goethe University Frankfurt, Vienna University of Economics and Business \&
\end{abstract}

CESifo)

17 May 2018

\begin{abstract}
This paper studies the distributional consequences of a systematic variation in expenditure shares and prices. Using European Union Household Budget Surveys and Harmonized Index of Consumer Prices data, we construct household-specific price indices and reveal the existence of a pro-rich inflation in Europe. Particularly, over the period 2001-15, the consumption bundles of the poorest deciles in 25 European countries have, on average, become 10.5 percentage points more expensive than those of the richest decile. We find that ignoring the differential inflation across the distribution underestimates the change in the Gini (based on consumption expenditure) by up to 0.03 points. Cross-country heterogeneity in this change is large enough to alter the inequality ranking of numerous countries. The average inflation effect we detect is almost as large as the change in the standard Gini measure over the period of interest.
\end{abstract}

Keywords: Inequality, Gini, EU countries, income dependent inflation

JEL classification: D31

Addresses of authors:

Alfons Weichenrieder

Goethe University Frankfurt

Eren Gürer

Faculty of Economics and Business

Goethe University Frankfurt

Administration

60323 Frankfurt (Main)

a.weichenrieder@em.uni-frankfurt.de

Faculty of Economics and Business

Administration

60323 Frankfurt (Main)

guerer@wiwi.uni-frankfurt.de

\#We thank Eurostat for granting access to the microdata on European Household Budget Surveys and Harmonized Index of Consumer Prices, Ariana Gilbert-Mongelli and Jeremy Edwards as well as the participants of $11^{\text {th }}$ RGS Doctoral Conference and 2018 ZEW Public Finance Conference for providing valuable comments. This paper is part of the research program of the LOEWE Center 'Sustainable Architecture for Finance in Europe' (SAFE). 


\section{Introduction}

Heterogeneous changes in consumer prices have become prevalent in recent decades. If the variation in expenditure shares of households and price changes is systematic, price changes may contribute to economic inequality, a situation which goes unnoticed by using a common CPI. In this paper, we construct household-specific price indices in order to capture the particular inflation experience (the effective inflation rate) of each household and highlight the role of income dependent inflation rates on inequality.

For the period 2001-2015, our results show that, on average, across 25 EU countries, the aggregated effective inflation rate for the lowest decile was 10.5 percent higher than for the top decile. This finding implies an average yearly inflation rate differential of 0.72 percentage points. We show that this "pro-rich inflation" translates into a considerable increase in inequality that is not reflected in standard measures of inequality. Particularly, ignoring the differential effective inflation rates across the distribution causes underestimation of the changes in the consumption expenditure Gini of up to 0.03 points. Cross-country heterogeneity in this effect is sizeable enough to move the placement of numerous countries in the ranking of inequality. We find that, while the average change in the standard Gini across $25 \mathrm{EU}$ countries is 0.020 over 2001-15, the average magnitude of underestimation arising from ignoring the differential effective inflation rates is 0.015 .

We are not the first to highlight the possibility of differing effective inflation rates for various household groups. One strand of the literature explores heterogeneity in the effective inflation rates across the distribution as well as across other demographic characteristics such as age, household size, gender, etc. (see, e.g., Michael (1979), Hagemann (1982), Garner et. al. (1996), Hobjin and Lagakos (2005), Murphy et. al. (2008), Oosthuizen (2013)). More relevant to our work, some scholars investigated the distributional consequences of the phenomenon of the differential effective inflation rates (see, e.g., Muellbauer (1974), Cage et. al. (2002), Crawford and Smith (2002), Garner et. al. (2003)). 
Recent contributions have substantially improved our understanding regarding the evolution of inequality. ${ }^{1}$ Yet, the possibility that the differential effective inflation rates could obscure the picture drawn by usual methods of measuring inequality has been largely neglected, particularly for developed economies. Arndt et al. (2015) and Beck (2015) focus on some African countries with a particular emphasis on the 2008 Global Food Crisis. Due to data limitations, they explore only three categories ("Core Food", "Non-core Food" and "Non-Food") in their analyses. While Arndt et al. (2015) find that accounting for heterogeneity in the effective inflation rates yields a higher inequality in Mozambique, results by Beck (2015) indicate heterogeneous effects across multiple African countries. Focusing on South America, Goni et al. (2006) study the same issue utilizing six expenditure categories and conclude that the inflation is anti-rich among countries of interest, except in Mexico. Another recent strand of the literature concentrates on green policies and energy prices and analyzes the resulting distributional concerns. See OECD (2006) or Neuhoff et al. (2013).

To the best of our knowledge, our study is the first to analyze this phenomenon in $25 \mathrm{EU}$ countries with as much as 30 expenditure categories over the post 2000 period.

It is worth noting that our analyses are mainly concerned with price variations in the upper-level expenditure categories (betweencategory). There is a growing body of literature using supermarket scanner data to investigate similar issues among specific lower-level categories (within-category), particularly for the US. See, e.g., Argente and Lee (2017), Jaravel (2017), and Faber and Fally (2017). Given the lack of comparable data for a wide set of European countries, within-category effects are beyond the scope of our paper.

The remainder of this paper is organized as follows. Section 2 formally shows the impact of a systematic variation in expenditure shares and prices. Section 3 describes the datasets used in this study

\footnotetext{
1 In Anglo-Saxon countries, much of the gains of economic growth has benefitted disproportionally the richest of the population. The development of increased levels of inequality is less clear in continental Europe. See, e.g., Atkinson, Piketty and Saez (2011) and Piketty and Saez (2014).
} 
and briefly illustrates the construction of household-specific price indices. Section 4 presents the main results, and Section 5 concludes.

\section{Conceptual Framework}

The departure point of this study is that expenditure shares usually vary across households and prices vary across items. If poorer (or richer) households spend a higher fraction of their income on particular groups of goods, and if the prices of those groups of goods are increasing rapidly, then inflation affects various households in different ways. A uniform Consumer Price Index (CPI) cannot accurately capture this heterogeneous impact across households. Consider the simple example of luxuries and necessities. Since the work of Ernst Engel (1857), it has become well-established that poorer households tend to spend a higher fraction of their income on necessities; whereas, richer ones can afford to spend more on luxury items. If the prices of necessities are increasing faster than the CPI, poorer households experience a larger decline in their real income.

It is helpful to formalize the idea of the previous paragraph. ${ }^{2}$ Let indirect (money-metric) utility of household $i$ be given by $V_{t}^{i}$. Let the growth rate of a variable $x_{t}$ with respect to a base period be denoted by $\hat{x}_{t} \equiv \frac{x_{t}}{x_{t_{0}}}-1$. Then, the change in the indirect utility of household $i$ may be approximated by

$$
\widehat{V}_{t}^{i}=\widehat{W}_{t}^{i}-\sum_{g \in G} s_{g}^{i} \hat{p}_{g, t}
$$

In Equation (1), $W_{t}^{i}$ represents the nominal income of household $i$ at time $t, s_{g}^{i}$ is the expenditure share on good $g$ and $\hat{p}_{g, t}$ is the relative increase in price of good $g$ with respect to the base year. Rewriting this equation as follows illustrates the impact of a systematic change in prices and expenditure shares.

\footnotetext{
2 Cravino and Levchenko (2017) use the same framework in a slightly different context; they assess the distributional consequences of 1994 Mexican devaluation.
} 


$$
\widehat{V}_{t}^{i}=\widehat{W}_{t}^{i}-\sum_{g \in G} s_{g} \hat{p}_{g, t}-\sum_{g \in G} \hat{p}_{g, t}\left(s_{g}^{i}-s_{g}\right)
$$

Equation (2) expresses the change in the indirect utility of household $i$. The first term on the right hand side is the nominal income. Given that $s_{g}$ is the aggregate expenditure share of good $g$ in the whole economy, the second term on the right hand side can be thought of as the impact of the standard CPI. If expenditure shares of each household were equal to the aggregate expenditure shares in the whole economy $\left(s_{g}\right)$, subtracting the second term would be sufficient to find any change in the indirect utility of the corresponding household. However, given that $s_{g}^{i}$ deviates from $s_{g}$, the third term may also have an impact on $\hat{V}_{t}^{i}$. This term will be non-zero, if the $\operatorname{Cov}\left(\hat{p}_{g, t}, s_{g}^{i}-s_{g}\right)$ is non-zero. Turning back to the point made at the very beginning of this section, this covariance term indicates whether or not the expenditure shares and change in prices is systematic. If it is not, then the third term is zero. If it is different from zero, this covariance term captures the heterogeneous effect of the price changes. For example, suppose household $i$ is poor and there are only necessities $(n)$ and luxuries $(l)$. As mentioned above, a given household tends to spend a higher fraction of its income on necessities. This implies $s_{n}^{i}-s_{n}>0$. If prices of necessities are increasing faster than luxuries $\left(\hat{p}_{n, t}>\hat{p}_{l, t}\right)$, then the third term is negative, indicating additional damage to its indirect utility.

As in Cravino and Levchenko (2017), a natural interpretation of this framework is heterogeneity in compensating variation. In essence, our analysis could provide an answer to the following question: Given the changes in prices, what should be the change in the nominal income of household $i$ such that it can afford the initial consumption bundle, whilst maintaining its utility unchanged? 


\section{Data and Calculation of the Household-specific Price Index}

\subsection{Data}

The primary data set used in this study is the European Union Household Budget Surveys (HBSs). They are conducted in all EU Member States with the aim of calculating national weights for the Consumer Price Index (CPI) and Harmonised Index of Consumer Prices (HICP). These surveys are nationally representative and collect detailed expenditure information for each household. Variables are harmonized across countries in order to calculate aggregates at the EU level. Although the statistical office of the European Union, Eurostat, has been conducting and publishing main aggregates of the surveys every five years since 1988, only the 2010 wave of microeconomic data is available for researchers. The 2010 wave incorporates data for 26 countries with an effective total sample size of over 270,000 households.

HBSs, however, lack information on prices. Therefore, we exploit a second data set, the Harmonised Index of Consumer Prices (HICP), provided by Eurostat. HICP contains country-year observations of a comparable measure of the changes in the prices of goods and services in the European Union with respect to a particular base year. Although the time series starts in 1996, a significant amount of data were missing until 2001. Therefore, this study only uses the price data between 2001 and 2015. In this context, a natural selection for the base year is 2001 .

Some problems that we encounter in linking HICP to HBSs are worth mentioning here. The first problem is to construct consistent expenditure categories across countries that match available price data. HBSs contain a comprehensive coverage of expenditures on many aggregation levels, represented by number of digits in the variable codes. For example, the 2-digit category "Food and Nonalcoholic Beverages" is split into two 3-digit categories "Food" and 
"Non-alcoholic Beverages". The 3-digit category "Food" is further split into 4-digit categories such as "Bread and Cereals", "Meat", etc. As mentioned above, one of the purposes of HBSs is to calculate weights for HICP. For this reason, the breakdown of consumption expenditure categories is identical in both data sets. Thus, mapping HICP data to HBSs does not require any additional procedures. However, even after 2001, HICP data is not available for all years at each aggregation level. This makes it impossible to use the most disaggregated categories when calculating expenditure shares. We could, however, partition the total consumption expenditure of each household to 30 expenditure categories (a combination of 2-digit and 3-digit categories) on which price data is available. Additional information on these 30 categories and their construction can be found in Appendix A (Table A.1). The second problem is that for Croatia, most of the time series of the price data begins in 2005. Because, in this case, it was not possible to select 2001 as the base year for Croatia, we have dropped it from our analysis. Ultimately, our final data set incorporates expenditure data of 30 categories for households in 25 EU countries together with the prices of these categories from 2001 to 2015. The list of 25 countries can be found in the Appendix A (Table A.2).

\subsection{The Calculation of Household-Specific Price Indices}

Equipped with prices and expenditure shares, we can turn to the empirical methodology behind computing the household-specific price indices. In essence, the price index of household $i$ at time $t$ can be denoted by

$$
q_{t}^{i}=\sum_{g=1}^{30} s_{g}^{i} \frac{p_{g, t}}{p_{g, t_{0}}}
$$

where $s_{g}^{i}$ is expenditure share on good $g, p_{g, t}$ is price of good $g$ at time $t$ and $p_{g, t_{0}}$ is price of the same good at the base year (2001 in our case). For each household in our sample, we calculate the expenditure 
share of every expenditure category. Taking 2001 prices as 1, we compute the price of each category in each year. Subsequently, multiplying expenditure shares with the prices of the corresponding categories and summing them over 30 categories for each household yields the household specific price-indices.

In Equation (3), note that expenditure shares of households $\left(s_{g}^{i}\right)$ do not have a time index. We recognize that observing expenditure shares of each household in each year would be ideal for the purposes of the study. However, as mentioned in the data section, we only have access to the 2010 wave of HBSs. Limitations brought about because of this restriction are discussed below. For now, it is sufficient to touch on some points in the literature of price indices and shed some light on theoretical insights related to this point.

Two most commonly employed price indices in the calculation of inflation are the Laspeyres and Paasche indices. Equations (4) and (5) provide their formulae.

$$
\begin{aligned}
& \text { Laspeyres Price Index: } q_{t}^{i}=\sum_{g \in G} s_{g, t_{0}}^{i} \frac{p_{g, t}}{p_{g, t_{0}}} \\
& \text { Paasche Price Index: } \quad q_{t}^{i}=\sum_{g \in G} s_{g, t}^{i} \frac{p_{g, t}}{p_{g, t_{0}}}
\end{aligned}
$$

The simple difference is that the Laspeyres Price Index takes the expenditure shares from the base period $\left(t_{0}\right)$ as opposed to Paasche Price Index which takes expenditure shares from the last period. This is the very reason that the Paasche Price Index is regarded as the lower bound of the cost-of-living index, whereas the Laspeyres Price Index is considered as the upper bound of the cost-of-living index. Economic theory suggests that agents minimize their expenditure given their level of utility. If this is the case, it is reasonable to expect that households substitute away from goods with higher prices in order to maintain a similar level of utility. Using a Paasche Price Index is useful in capturing this substitution effect and provides the minimum cost-of-living, at a given point in time, with respect to a base year. Therefore, it has been employed as the main empirical 
strategy in similar studies (see e.g.; Arndt et al. (2015), Beck (2015), Goni et al. (2006)).

Returning to this study, it should be kept in mind that our analysis covers the time period 2001-15 while using expenditure share observations from 2010. By using the Paasche Price Index, the period 2001-10 is in line with the contributions mentioned in the previous paragraph. However, between 2010 and 2015, effectively, we switch to the Laspeyres Price Index. Given our main finding of pro-rich inflation, this does not undermine our results. If the rich are more able to substitute away certain goods in response to a price increase, their inflation exposure over 2010-15 is overestimated. This occurs because we do not capture the substitution effect over this later period which is possibly favoring the rich. Therefore, if anything, our results regarding pro-rich inflation most likely give the lower bound. In this framework, our assumption regarding substitution ability of rich versus poor households is crucial. In Appendix B, we provide a simple model with Stone-Geary preferences. Our model supports the assumption that richer households have a greater ability to substitute away from certain goods in response to a price increase.

\section{Results}

\subsection{Pro-rich Inflation in Europe}

This section provides evidence of pro-rich inflation in Europe. To begin, Table 1 presents the evolution of prices. Numbers reported in the table are unweighted means of the percentage increases in prices with respect to a base year across 25 EU countries. Between columns 1 and 3, the period of interest is split into three intervals and the percentage increase in the price of the corresponding category is reported with respect to the beginning of the interval. The last column provides the overall increases in prices from 2001 to 2015.

An analysis of Table 1 reveals rather important clues regarding the main results. The first row of the table reports the average CPI across countries. The average price increase for all goods and services across 
Europe between $2001-15$ is $44.68 \%$. Categories that can naively be classified as necessities (i.e., the ones concerning food and housing) have experienced larger price increases, on average. For example, between 2001 and 2015, price of "Water supply and misc. services" (044) has increased by $137.73 \%$, "Electricity, gas and other fuels" (045) by $106.21 \%$, "Actual rentals of housing” (041) by 69.74\%, "Food" (011) by $47.54 \%$. Conversely, price increases in luxury-type categories, such as "Recreation and culture" (09), "Glassware, tableware and household utensils" (054), "Purchase of vehicles" (071) have stayed below the common CPI.

Figure 1 plots the price increases of 30 expenditure categories (see last column of Table 1) against the unweighted average of aggregate expenditure shares of the same categories across 25 countries, between 2001-15. The red line parallel to the $\mathrm{x}$-axis represents the simple mean of the common CPIs (last column of the first row of Table 1) and the red line parallel to the $y$-axis represents the mean of the average aggregate expenditure shares.

Figure 1 is informative in two dimensions. It provides evidence on the relative price increases and the relative size of the expenditure share for each category. For example, take "Food" (011). The aggregate average expenditure share across Europe is around $16 \%$. Comparing this to the straight $\mathrm{y}$-line, one can conclude that relative share of "Food" in household budgets is well above average. Its price has increased slightly faster than the common CPI (red y-line). The price of "Tobacco" (022), on the other hand, has tripled, but its expenditure share is below average. 


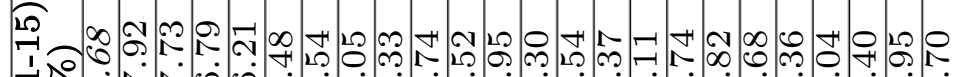
-

a.

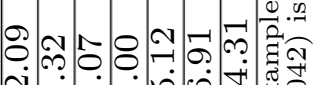

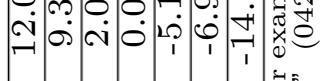

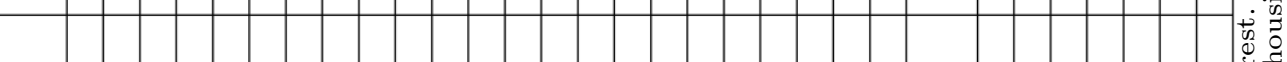

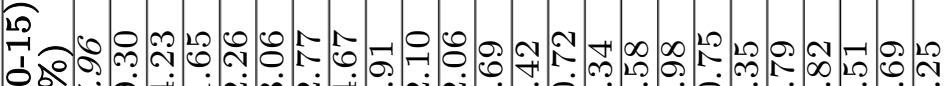

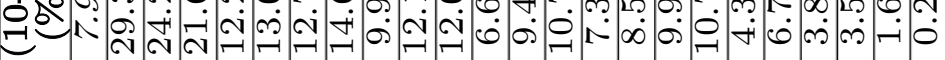

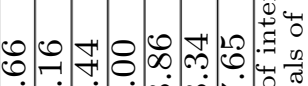
a.

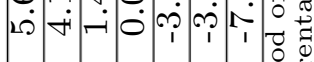

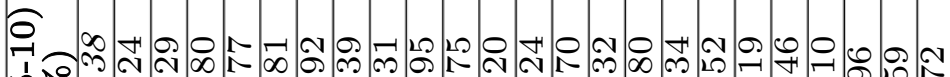

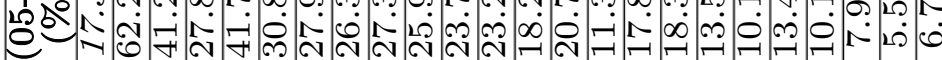
a

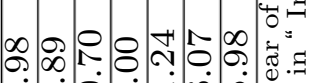

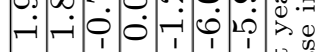

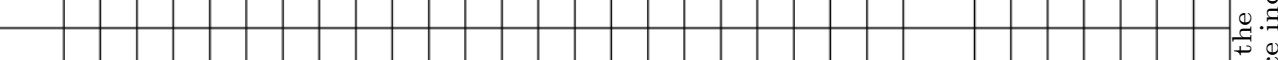

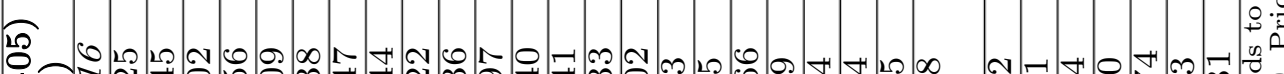

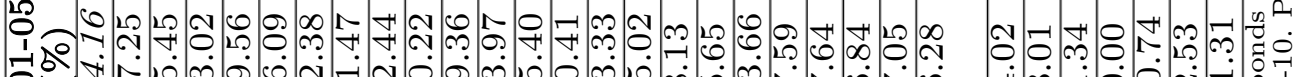
é a 


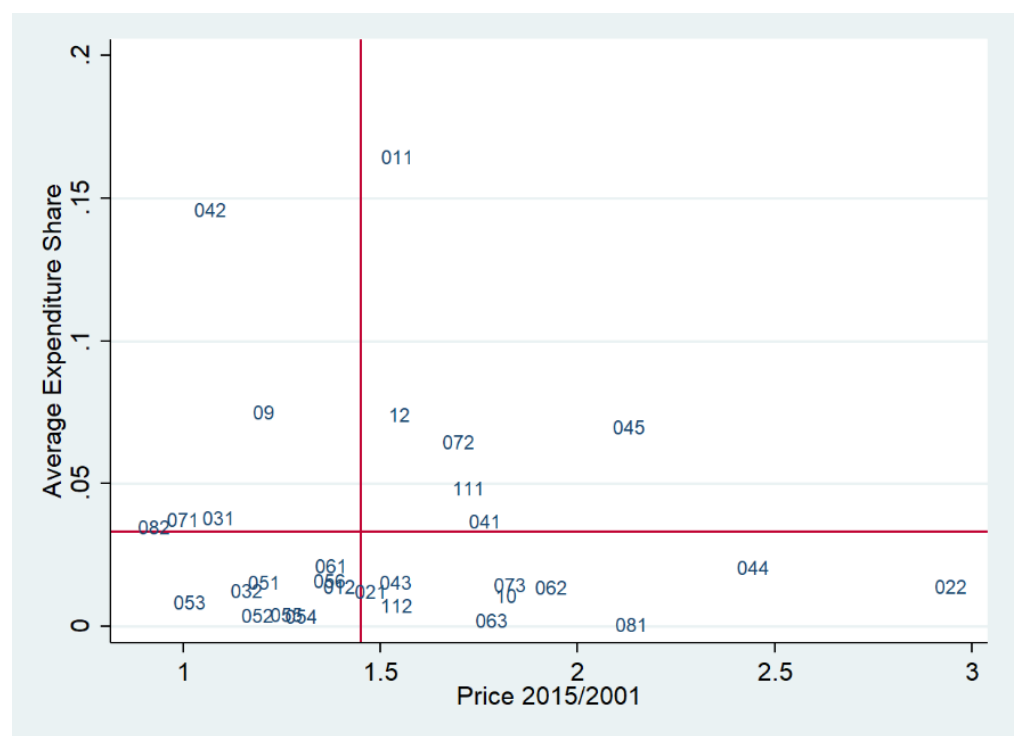

Notes: A numerically ordered listing of the category codes can be found in Appendix $A$ (Table A.1). The red line parallel to the $x$-axis represents the mean of the common $C P I_{S}$. The red line parallel to the $y$-axis indicates the mean of the aggregate expenditure shares of 30 categories across countries.

So far, we have ignored the fact that expenditure shares vary with household income. To better capture this phenomenon, Figure 2 takes categories that have an above average share ${ }^{3}$ and illustrates their expenditure shares across consumption expenditure deciles. Values are simple means of expenditure shares of deciles across all 25 countries. Items depicted in red experienced a price increase above the common CPI, whereas items in blue had a price increase below the common CPI for the corresponding categories over the period 2001-15. Items are in ascending order from the top to the bottom in terms of their price increase. The ten largest expenditure categories sum up to approximately $65-70 \%$ of the total expenditure across deciles. Close to $60 \%$ of the poorest decile's expenditure is exposed to a price increase above the common CPI; this share for the richest decile is around $40 \%$. Analyzing categories one by one reveals some important information regarding the source of this differential. Expenditure

\footnotetext{
${ }^{3}$ We exclude "Imputed rentals of housing" (042) from Figure 2. See Appendix A for details on data preparation.
} 
shares of "Food" (011), "Electricity, gas and other fuels" (045) and "Actual rentals of housing" (041) are monotonically declining from lower to upper deciles and their prices have been increasing above average. Conversely, "Recreation and culture" (09) and "Purchase of vehicles" (071) constitute higher expenditure shares for richer deciles and their price increases have been below average. These five expenditure categories are potential drivers for pro-rich inflation in Europe.

Figure 2: Breakdown of Expenditure Shares above or below the Common CPI by Decile

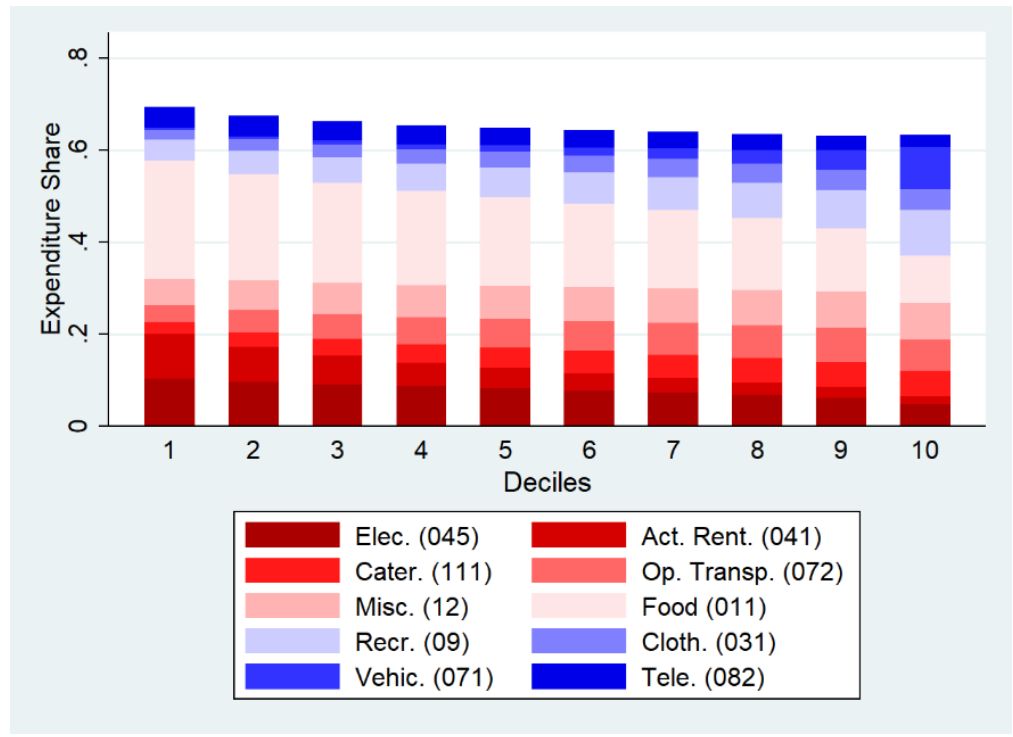

Notes: Explanations of the category codes can be found in Appendix A (Table A.1). Items represented in red (blue) had a price increase above (below) the common CPI over the period 2001-15. Items are in ascending order from top to bottom in terms of their price increase.

Figure 3 provides a similar picture by including all expenditure categories. A simple conclusion of this figure is that around $65 \%$ of the expenditure basket of the poorest decile have been exposed to a price increase above the common CPI. The richest decile, on the other hand, has only seen around $50 \%$ of its basket's price increasing faster than average. 


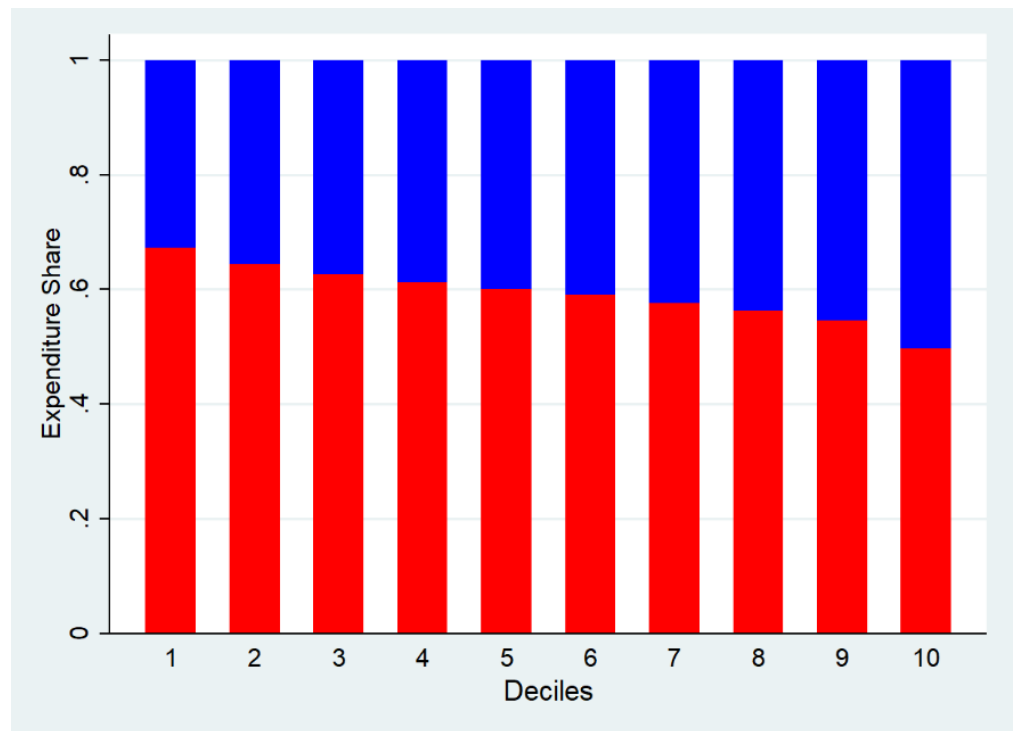

Notes: Fractions represented in red (blue) had a price increase above (below) the common CPI over the period 2001-15.

Our analysis continues with the point estimates of the differences in the effective inflation rates across deciles. Here we construct and make use of household-specific price indices. We average the household-specific price indices $\left(H H P I_{i, j, k, t}\right)$ in each decile $j$ of each country $k$ at time $t$ to compute $\overline{H H P I}_{j, k, t}$. For each country and decile, we calculate the simple difference of this measure between 2001 and 2015.

$$
\Delta \overline{H H P I}_{j, k}=\overline{H H P I}_{j, k, 2015}-\overline{H H P I}_{j, k, 2001}
$$

Note that $\overline{H H P I}_{j, k, 2001}$ equals 1 for each country and decile using 2001 as the base year. Hence, $\Delta \overline{H H P I}_{j, k}$ corresponds to the percentage points (or percentage) increase in the effective inflation rate of each decile in every country between 2001 and 2015. Subsequently, we run a standard t-test between $\Delta \overline{H H P I}_{j, k}$ of each decile $j$ where $j=1,2, \ldots, 9$ and $\Delta \overline{H H P I}_{10, k}$ across all 25 countries $(k)$. In other words, we compare the increases in the effective inflation rates of each decile with the $10^{\text {th }}$ decile across countries. Table 2 presents the results. 
Table 2: Comparison of the Increase in the Effective Inflation Rates with the 10 ${ }^{\text {th }}$ Decile (T-tests)

\begin{tabular}{cccccccccc}
\hline \hline Decile & 1 & 2 & 3 & 4 & 5 & 6 & 7 & 8 \\
\hline Difference & $\begin{array}{c}0.105^{* * *} \\
(0.015)\end{array}$ & $\begin{array}{c}0.092^{* * *} \\
(0.013)\end{array}$ & $\begin{array}{c}0.087^{* * *} \\
(0.012)\end{array}$ & $\begin{array}{c}0.075^{* * *} \\
(0.011)\end{array}$ & $\begin{array}{c}0.073^{* * *} \\
(0.012)\end{array}$ & $\begin{array}{c}0.064^{* * *}(0.010) \\
0.055^{* * *} \\
(0.009)\end{array}$ & $\begin{array}{c}0.046^{* * *} \\
(0.009)\end{array}$ & $0.035^{* * *}$ \\
$(0.008)$ \\
$\begin{array}{c}\text { Implied Yearly } \\
\text { Difference }\end{array}$ & 0.72 & 0.63 & 0.60 & 0.52 & 0.50 & 0.44 & 0.38 & 0.32 & 0.25 \\
\hline \hline
\end{tabular}

Note: ${ }^{* * *}$ denotes the significance level at $1 \%$. Standard errors are reported in parentheses.

Point estimates are consistent with the trend observed in Figure 3. The effective inflation rate is monotonically increasing as we move to poorer deciles. Between 2001 and 2015, the expenditure basket of the poorest decile in each country became on average 10.5 percentage points more expensive compared to the richest decile. The difference is statistically significant at the $1 \%$ level. The third row in Table 2 translates the total differences into implied average yearly differences. On average, the inflation rate of the poorest decile's basket exceeded the richest decile's basket by 0.72 percentage points, while the average common CPI was $2.67 \%$.

Next, we return to the issue pointed out at the end of Section 3.2. As explained there, the expenditure minimizing behavior of households ensures that the substitution effect is captured until 2010. Therefore, if we were to analyze effective inflation rate with prices over 2001-10 and the expenditure shares of 2010, results could be treated as the changes in the minimum-cost-of-living. However, our price data covers up to 2015. If the rich are more able to substitute away from goods in response to a price increase, as our model in Appendix B implies, not capturing the substitution effect between 2010-15 causes a stronger overestimation of the effective inflation rate for the rich and thus renders our point estimates as the lower bound. For example, suppose there has been a substantial increase in the prices of food between 2010-15. Given the finding of our model, the rich can substitute more costly food with other categories more effectively (e.g.; recreation and culture, beverages etc.) and maintain the same level of utility. Since our approach cannot account for substitution over the 2010-15 period, if anything, the effective inflation rate of the rich is overestimated. 
Finally, we investigate whether our results are only picking up on certain shocks in particular countries or years. We graph the evolution of the effective inflation rates of the poorest and the richest deciles in all countries across 2001-15. We compute the effective inflation rates of deciles as the simple mean of household-specific price indexes of the corresponding decile in a given country. The results are presented in Appendix C (Figure C.1). The aggregate trend found in this appendix holds for almost all countries. Portugal and Italy are notable exceptions. The differences in the effective inflation rates of the richest and the poorest deciles are increasing over time. Therefore, we conclude that our results is the outcome of a general recent trend in Europe.

\subsection{Implications for the Measurement of Inequality: A Thought Experiment}

For the final part of the analysis, we conduct a thought experiment in order to evaluate the implications of pro-rich inflation on the measurement of inequality. Suppose that, for all households in our sample, the 2010 nominal consumption expenditure was constant across the period 2001-15. Starting from this point of comparison, how would consumption inequality be affected, if we account for the different evolution of prices by applying household-specific price indices?

Our strategy is as follows. Let $C_{i, k, t}^{C}$ denote the consumption expenditure of household $i$ in country $k$ at time $t$ deflated by the common CPI:

$$
C_{i, k, t}^{C}=\frac{C_{i, k, 2010}^{N}}{p_{k, t} m\left(h_{i}\right)}
$$

where $C_{i, k, 2010}^{N}$ is the nominal consumption expenditure of the same household, $p_{k, t}$ is the common CPI of country $k$ at time $t$ and $m\left(h_{i}\right)$ is 
the household equivalence scale ${ }^{4}$. The function $f: R_{+}^{N} \rightarrow R_{+}$maps the consumption values into an inequality index (e.g., Gini index). Then, inequality in country $k$ after applying the common CPI to nominal consumption expenditure values of households is given by $f\left(\vec{C}_{k, t}^{c}\right)$, which is our baseline inequality measure. Here, $\vec{C}_{k, t}^{C}$ denotes the vector of country $k^{\prime}$ s household incomes, $C_{i, k, t}^{C}$. Note that $f\left(\vec{C}_{k, t}^{C}\right)$ is constant across the period of interest. Our thought experiment assumes $C_{i, k, t}^{N}=$ $C_{i, k, 2010}^{N}$ over 2001-15. Then, the only time varying term in the calculation of $C_{i, k, t}^{C}$ is $p_{k, t}$. Given that inequality measures are mean independent, our baseline inequality measure for each year is the consumption expenditure inequality in 2010.

Subsequently, we calculate consumption expenditures of household $i$ in country $k$ at time $t$ deflated by household-specific price index $p_{i, k, t}$ according to the following formula.

$$
C_{i, k, t}^{H H}=\frac{C_{i, k, 2010}^{N}}{p_{i, k, t} m\left(h_{i}\right)} \quad \text { where } \quad p_{i, k, t}=\sum_{j=1}^{30} s_{j, i, k} q_{j, k, t}
$$

In Equation (8), $s_{j, i, k}$ is the expenditure share of household $i$ in country $k$ on expenditure category $j$. (Note that it lacks a time index because the thought experiment assumes that households consume the same bundle of goods and services across 2001-15.) $q_{j, k, t}$ is the price of expenditure category $j$ in country $k$ at time $t$ with respect to the base year (2001 in our case). Inequality in country $k$ after deflating nominal consumption values with household-specific price indexes is given by $f\left(\vec{C}_{k, t}^{H H}\right)$, where $\vec{C}_{k, t}^{H H}$ is the vector of all real household consumption levels, $C_{i, k, t}^{H H}$. Finally, the difference between two inequality measures at time $t$ yields the change coming from ignoring the heterogeneity in the effective inflation rates.

\footnotetext{
${ }^{4}$ In particular, we use the modified OECD equivalence scale which assigns 1 to head of household, 0.5 to each additional adult member and 0.3 to each child.
} 


$$
\text { Change }_{k, t}=f\left(\vec{C}_{k, t}^{H H}\right)-f\left(\vec{C}_{k, t}^{C}\right)
$$

Figure 4 presents the evolution of Change $_{k, t}$ over 2001-15. If the prorich inflation is a general trend in Europe and the gap in the effective inflation rates between rich and poor is increasing over time, as we found in the previous section, we should find a positive and increasing difference between $f\left(\vec{C}_{k, t}^{H H}\right)$ and baseline inequality measures $f\left(\vec{C}_{k, t}^{C}\right)$. Indeed, in all of the countries, except Italy and Portugal, the Gini coefficient is higher once the household-specific price indices are accounted for. Results reveal that in most of the European countries, inequality measures that ignore the effective inflation rate differentials across the distribution yield an underestimation of the change in inequality over the period 2001-15. The magnitude of Change $_{k, t}$ is generally rising over time, as seen below in Figure 4.

Figure 4: Differences in Inequality Measures (Change ${ }_{k, t}$ ) by Country
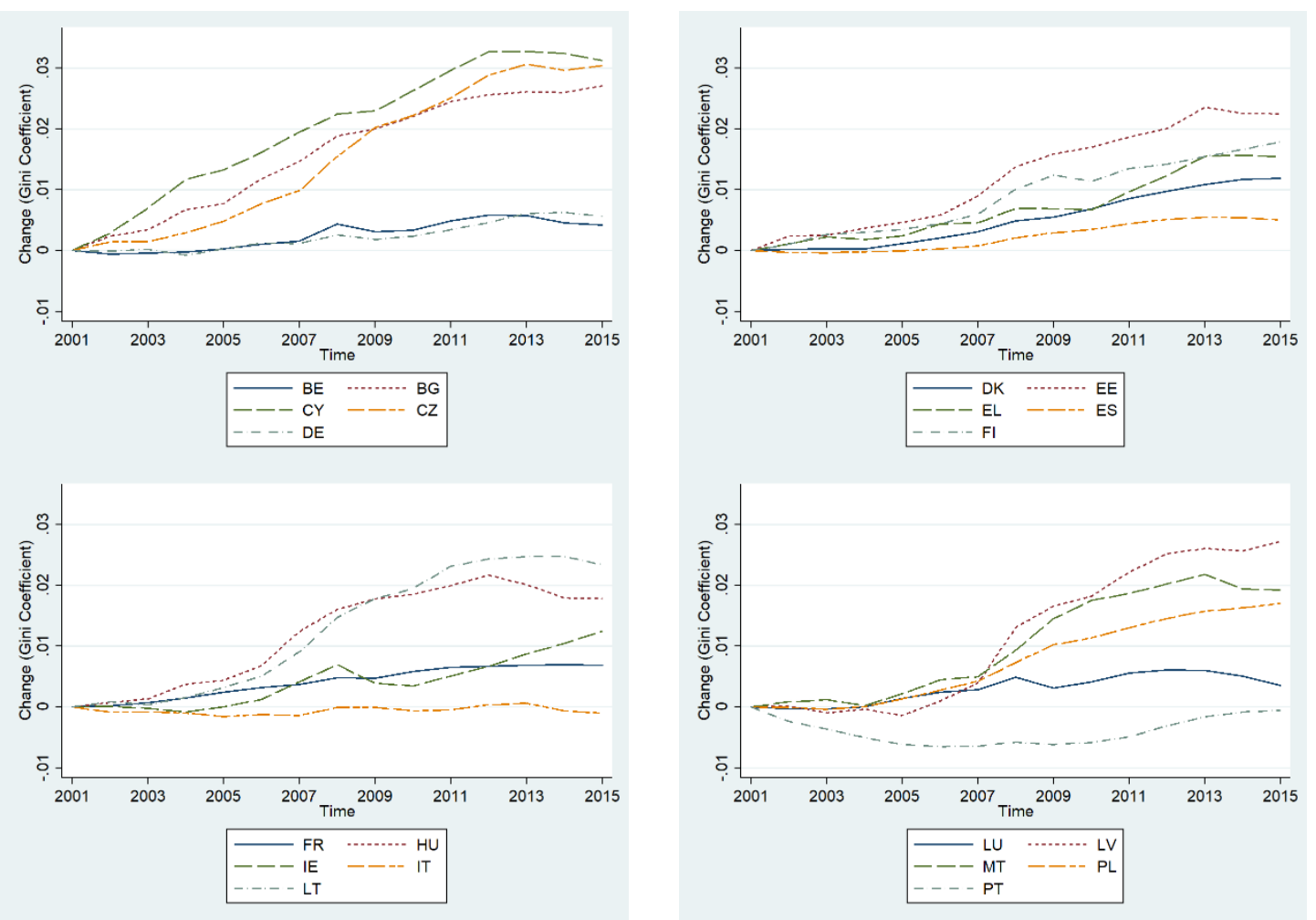


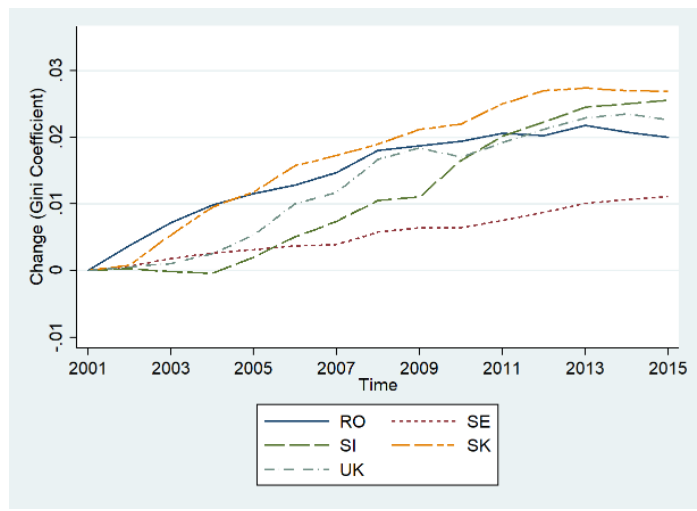

Notes: Country abbreviations can be found in Appendix A (Table A.2)

Figure 5: Absolute Change in Gini Index after Applying Household-specific Price Indices

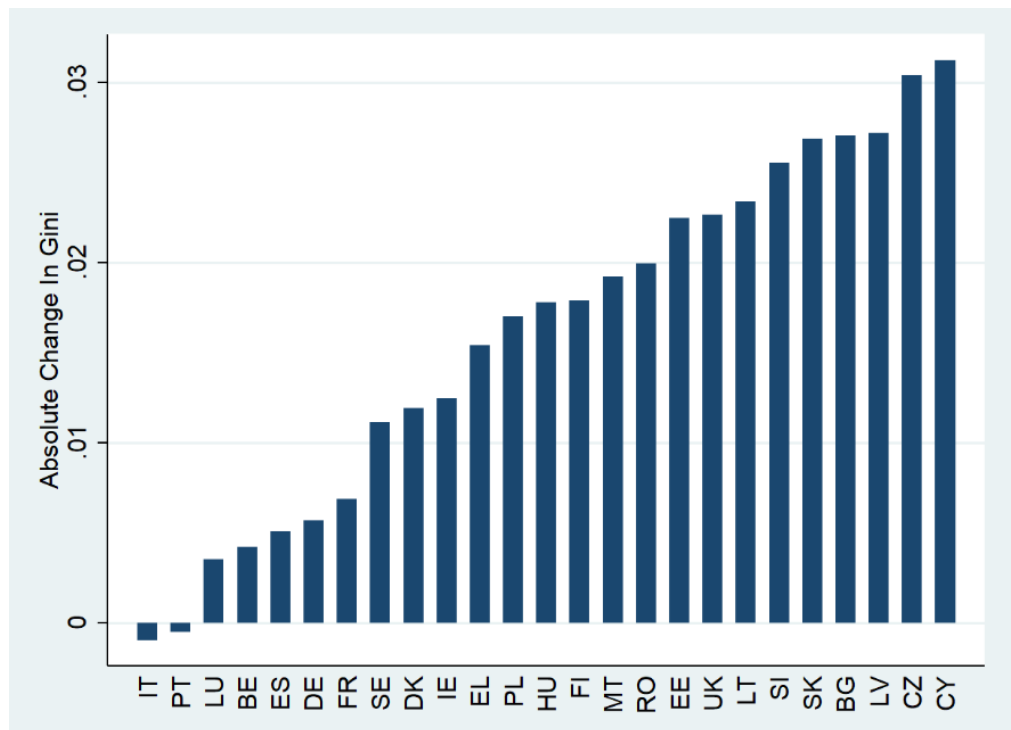

Notes: Country abbreviations can be found in Appendix A (Table A.2)

Furthermore, we explore the magnitude and cross-country heterogeneity of Change $_{t}$. We graph Change $_{k, t}$ at 2015 (last data points of Figure 4) in Figure 5. Over the period of interest, the total impact of the differential effective inflation rates on the Gini coefficient goes up to 0.03. Table 3 presents baseline inequality measures $f\left(\vec{C}_{k, t}^{C}\right)$ and The Adjusted Gini Indices $f\left(\vec{C}_{k, t}^{H H}\right)$ by country. Cross-country heterogeneity in magnitudes of the errors are large enough to change the inequality ranking of numerous countries. See the fourth column in Table 3 for adjusted Gini indices. For example, although Italy is 
considered the sixth most unequal country on the baseline list, it moves to the ninth position after accounting for the error in the adjusted index. Portugal, the second most unequal country, moves to fifth position on the modified list.

Whether pro-rich inflation leads overall to more unequal distributions depends on whether the effect of inflation on the Gini and the effect from the development of nominal consumption levels on the Gini are positively or negatively correlated. For example, it is possible that countries with a stronger pro-rich inflation had more progressive policies favoring poorer households which in turn compensated for the inflation effect. Because the European HBS that is used in this paper contains consumption data for 2010 only, we rely on the available development of the income Gini (Eurostat, 2017) to check for a possible correlation with the amount of pro-rich inflation.

Table 3: Baseline $\left(f\left(\vec{C}_{k, t}^{C}\right)\right)$ and Adjusted $\left(f\left(\vec{C}_{k, 2015}^{H H}\right)\right)$ Gini Indices by Country

\begin{tabular}{|c|c|c|c|c|}
\hline Country & Gini Index & Rank & $\begin{array}{l}\text { Adjusted Gini } \\
\text { Index }\end{array}$ & Rank \\
\hline Estonia & 0.333 & 1 & 0.356 & 1 \\
\hline Portugal & 0.332 & 2 & 0.331 & 5 \\
\hline Malta & 0.328 & 3 & 0.347 & 2 \\
\hline Latvia & 0.315 & 4 & 0.343 & 3 \\
\hline United Kingdom & 0.315 & 5 & 0.338 & 4 \\
\hline Italy & 0.308 & 6 & 0.307 & 9 \\
\hline Greece & 0.302 & 7 & 0.318 & 7 \\
\hline Cyprus & 0.294 & 8 & 0.325 & 6 \\
\hline Lithuania & 0.293 & 9 & 0.316 & 8 \\
\hline Poland & 0.285 & 10 & 0.302 & 10 \\
\hline Finland & 0.284 & 11 & 0.302 & 11 \\
\hline Spain & 0.282 & 12 & 0.287 & 14 \\
\hline France & 0.281 & 13 & 0.288 & 13 \\
\hline Germany & 0.279 & 14 & 0.285 & 16 \\
\hline Luxembourg & 0.277 & 15 & 0.281 & 18 \\
\hline Romania & 0.277 & 16 & 0.297 & 12 \\
\hline Belgium & 0.260 & 17 & 0.265 & 20 \\
\hline Ireland & 0.260 & 18 & 0.273 & 19 \\
\hline Bulgaria & 0.259 & 19 & 0.286 & 15 \\
\hline Slovenia & 0.257 & 20 & 0.283 & 17 \\
\hline Hungary & 0.244 & 21 & 0.262 & 21 \\
\hline Sweden & 0.240 & 22 & 0.251 & 23 \\
\hline Denmark & 0.230 & 23 & 0.242 & 24 \\
\hline Slovakia & 0.225 & 24 & 0.251 & 22 \\
\hline Czech Republic & 0.206 & 25 & 0.236 & 25 \\
\hline
\end{tabular}

Notes: The Adjusted Gini Index is calculated after correcting nominal consumption expenditures of households in 2010 by the benefit (or disadvantage) derived as household-specific price indices decreased (or increased) compared to the general CPI during the period 2001-2015. The adjusted Index equals the Gini index in column 2, plus the inflation effects indicated in Figure 5. 
Figure 6 illustrates the results. For each country in our sample, the y-axis measures the difference in the Gini between 2001 and 2015. This Gini relies on disposable income, and the change captured here ignores household-specific inflation. On the x-axis, we plot the change in the Gini that would have resulted from inflation effects only, as reported in Figure 5. From this exercise, we find an insignificantly positive correlation. This suggests that the inflation effect on the distribution identified above, has not been compensated by a systematic income development. Figure 6 also illustrates that, whereas between 2001 and 2015 the ordinary Gini on average increased by 0.020 points, the average effect of inflation was slightly lower, around 0.015. The inflation effects were almost as important as the changes in the income Gini arising from the actual development of incomes.

Figure 6: Correlation of Inflation Effects on the Gini and Changes in the Income Gini

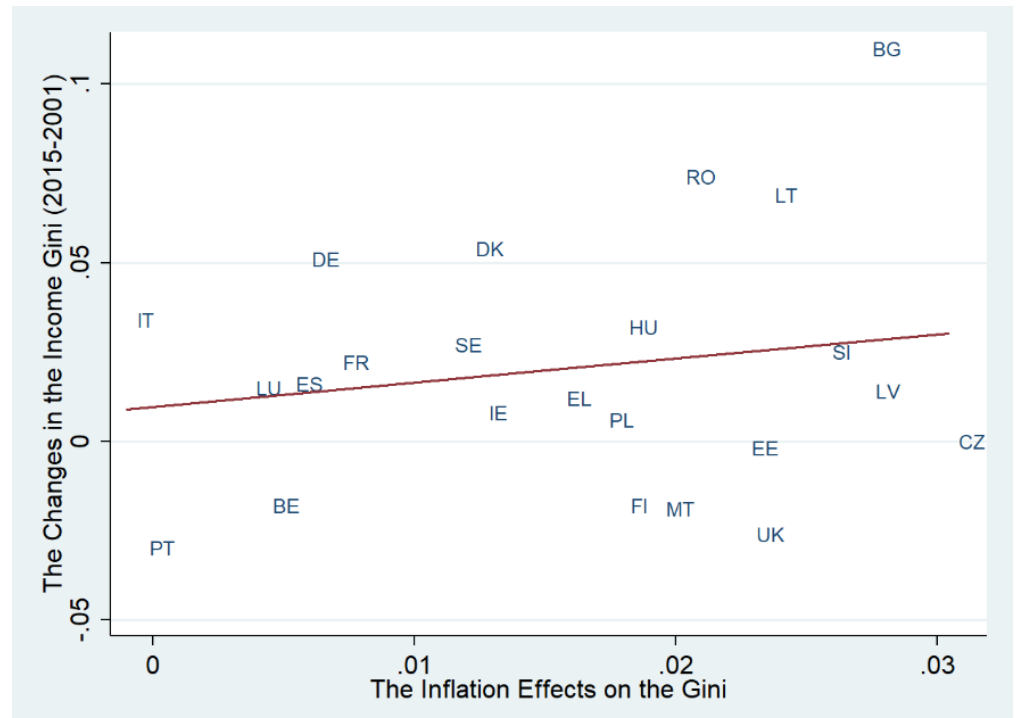

Notes: Country abbreviations can be found in Appendix A (Table A.2). In the main dataset, the income Gini of 2001 was missing for Cyprus, Latvia, Malta and Slovakia. We proxied it with the income Gini of 2000 for Latvia and Malta. The closest available income Gini data for Slovakia and Cyprus is 2005. Therefore, we excluded them from this figure.

In the literature on inequality measurement, it is argued that the Gini coefficient is overly sensitive to changes in the middle of the distribution (Atkinson, 1970, p. 256). Conversely, the variance of 
logarithms is known to be more sensitive to the changes at the tails. In order to make sure that the trend we found is robust to the use of the inequality measure, we repeat the exercise by taking the variance of logs as our inequality measure. In the interest of space, we only report the equivalents of Table 3 and Figure 5. Results are reported in Appendix D (Table D.1 and Figure D.1). Although there are small changes in the rankings of some countries, our main conclusions are robust.

Cross-country heterogeneity in magnitudes, presented in Figure 5, raises some interesting questions. What is the source of the differential effective inflation rates across the distribution? Why are some countries more affected than others? In order to investigate these questions, we graph the difference between expenditure shares of the richest and the poorest decile for 30 categories over the prices of the corresponding categories in 2015 (normalized by 2001 prices). Graphs presented in Appendix D (Figure D.2) provide a simple picture of each country to analyze the source of the effective inflation. In general, consistent with the findings of Section 4.1, it seems that in most countries, "Food" (011) and "Electricity, gas and other fuels" (045) are important drivers of the cross-country heterogeneity of the effective inflation. This leaves open questions concerning the extent to which either policy influences or general market trends are responsible for these developments. We leave this as an open question for future research.

\section{Conclusion}

Given the fact that expenditure shares vary across households and prices vary across items, this paper highlights the distributional consequences of a systematic variation in expenditure shares and prices. By its very nature, the common CPI does not capture the differential effect of such a variation across households. Combining the European Union Household Budget Surveys (HBSs) and the Harmonized Index of Consumer Prices (HICP) data from Eurostat, we build a data set with 30 expenditure categories for households in 
25 EU countries together with prices of these categories from 2001 to 2015. Subsequently, we construct household-specific price indices in order to account for the effective inflation rates of each household in our sample.

Our analysis suggests the existence of a pro-rich inflation in Europe over the period 2001-15. Our point estimates reveal that the poorest decile have seen their consumption bundle becoming 10.5 percentage points more expensive than the richest decile's; this translates into, on average, a 0.72 percentage point yearly difference. Our analysis highlights the importance of the substantial increase in the prices of "Food" (011), "Actual rentals of housing" (041) and "Electricity, gas and other fuels" (045) as some of the main drivers of this phenomenon. Among the $25 \mathrm{EU}$ countries we investigate, every one of them, except for Italy and Portugal, have experienced this trend, albeit with different magnitudes. Furthermore, we explore the implications of pro-rich inflation on the measurement of inequality. Our thought experiment indicates that accounting for the household-specific price indices increases the consumption expenditure Gini by up to 0.03 points. Cross-country heterogeneity in the magnitude of this change is large enough to slightly affect the inequality ranking of numerous countries. The average effect of inflation on the Gini ( 0.015 points) is almost as important as the average change in the usual Gini (0.020 points) across all 25 countries between 2001 and 2015 .

This paper does not provide a causal explanation for the source of the cross-country heterogeneity in pro-rich inflation. Exploring the specific channels that drive such a variation across countries, we believe, is an important area for future research. Moreover, as emphasized in the first section, our analysis only accounts for between-category variations in expenditure shares and prices. Using Nielsen data, an expanding body of literature is investigates the same question by exploring within-category variations for the US. It would be interesting to see how incorporating the within-category variations might change the outcomes found in this paper.

Finally, this paper may also explain the high degree of public interest in distributional issues on continental Europe, although many 
economic studies based on uniform consumer price indices for recent decades find only limited increases in income inequality in European countries. 


\section{Bibliograpy}

Argente, D. and M. Lee (2017), “Cost of Living Inequality during the Great Recession", Kilts Center for Marketing at Chicago Booth Nielsen Dataset Paper Series 1-032, Available at SSRN: https://ssrn.com/abstract $=2567357$.

Arndt, C., S. Jones and V. Salvucci (2015), "When do relative prices matter for measuring income inequality? The case of food prices in Mozambique", Journal of Economic Inequality 13(3), 449.

Atkinson, A. B. (1970), "On the measurement of inequality", Journal of Economic Theory 2(3), 244-263.

Atkinson, A. B., T. Piketty and E. Saez (2011), “Top incomes in the long run of history", Journal of Economic Literature, 49(1), 3-71.

Beck, U. (2015), Keep it real: Measuring real inequality using survey data from developing countries, (No. 2015/133) WIDER Working Paper.

Cage, R. A., T. Garner and J. Ruiz-Castillo (2002), Constructing household specific consumer price indexes: An analysis of different techniques and methods, BLS Working Paper 354, Washington DC: US Bureau of Labor Statistics.

Cravino, J., and A. A. Levchenko. (2017), "The distributional consequences of large devaluations", American Economic Review 107(11), 3477-3509.

Crawford, I., and Z. Smith (2002), Distributional aspects of inflation, IFS Commentary 90.

Engel, E. (1857), "Die Produktions-und konsumptionsverhältnisse des Königreichs Sachsen", Zeitschrift des Statistischen Bureaus des Königlich Sächsischen Ministeriums des Innern, 8, 1-54.

Eurostat (2017), "Gini coefficient of equivalised disposable income", Retrieved from: http://ec.europa.eu/eurostat/data/database on 14.02.2018.

Faber, B. and T. Fally (2017), Firm heterogeneity in consumption baskets: Evidence from home and store scanner data, NBER Working Paper 23101.

Garner, T. I., D. S. Johnson and M. F. Kokoski (1996), "An experimental consumer price index for the poor", Monthly Lab. Rev., 119, 32. 
Garner, T. I., J. Ruiz-Castillo and M. Sastre (2003), "The influence of demographics and household-specific price indices on consumption-based inequality and welfare: A comparison of Spain and the United States", Southern Economic Journal, 70(1), 22-48.

Goni, E., H. Lopez and L. Serven (2006), Getting real about inequality: Evidence from Brazil, Colombia, Mexico and Peru, Policy Research Working Paper WPS3815, Washington DC: World Bank.

Hagemann, R. P. (1982), "The variability of inflation rates across household types", Journal of Money, Credit and Banking, 14(4), 494-510.

Hobijn, B., and D. Lagakos (2005), "Inflation inequality in the United States", Review of Income and Wealth, 51(4), 581-606.

Jaravel, X. (2017) The Unequal Gains from Product Innovations: Evidence from the US Retail Sector, Working Paper, Harvard University.

Michael, R. T. (1979), "Variation across households in the rate of inflation", Journal of Money, Credit and Banking, 11(1), 32-46.

Muellbauer, J. (1974), "Prices and inequality: the United Kingdom experience”, Economic Journal, 84(333), 32-55.

Murphy, E., E. Garvey and S. O'Neill (2008), Cost of living for different social groups in Ireland, Combat Poverty Agency Working Paper Series, 08/03, Dublin.

Neuhoff, K., S. Bach, J. Diekmann, M. Beznoska, T. El-Laboudy (2013), "Distributional effects of energy transition: Impacts of renewable electricity support in Germany", Economics of Energy and Environmental Policy, 2(1), 41-54.

OECD (2006), The distributional effects of environmental policy, Paris: OECD.

Oosthuizen, M. (2013), Inflation inequality in South Africa, Working Papers 13158, University of Cape Town, Development Policy Research Unit.

Piketty, T., and E. Saez (2014), "Inequality in the long run", Science, 344(6186), 838-843. 


\section{Appendix A}

\section{Data Preparation}

\section{Construction of Consistent Categories from HBSs}

As it is mentioned in Section 3, HBSs contain consumption expenditure data in many aggregation levels which are represented by the number of digits in the variable codes, ranging from the 2- to 5digits. For example, the variable representing the consumption expenditure on "Food and Non-alcoholic Beverages" is 2-digit. Subcategories of the 2-digit level of aggregation, naturally, include 3-digit categories (e.g., food, non-alcoholic beverages). Although it would be ideal for the sake of precision, it is not possible to employ categories more disaggregated than the 3-digit ones used because there is a significant amount of missing price data.

A serious flaw in 3-digit categories is that in approximately $9 \%$ of the observations, 3-digit categories do not add up to their corresponding 2-digit aggregate. If, for example, the sum of the 3-digit category "Food" and the 3-digit category "Non-alcoholic Beverages" do not add up to their 2-digit aggregate "Food and Non-alcoholic Beverages", it is natural to expect that sum of all 3-digit categories would not add up to the total consumption expenditure. One approach would be to work with only the twelve 2-digit categories of the survey. However, because using the most disaggregated categories whenever possible increases precision, we deal with this issue by scaling up the 3-digit categories proportionately such that they will add up to their 2-digit aggregate.

In the HICP data, unfortunately, prices are not fully available on the 3-digit level. Therefore, we investigate every 3-digit category to see the extent of missing price data. If the number of missing data points is too large such that an imputation could create meaningless results, we use the 2-digit aggregate for that particular strand. For example, just like HBS data, the HICP data splits the 2-digit aggregate "Education" into 3-digit categories such as "Primary 
Education", "Secondary Education", etc., and reports prices both on the 2-digit and 3-digit level. If price data on the 3-digit level is missing in a significant number of country-year observations, we collapse that strand to its 2-digit aggregate and only use the 2-digit level in the analysis. If there are relatively few missing observations, then we impute them. Details of the imputation procedure are provided in the next section. Table A.1 presents the 30 expenditure categories and their codes. Table A.2 contains the list of 25 EU countries analyzed, along with their abbreviations.

Table A.1: Expenditure Categories and Variable Codes

\begin{tabular}{|c|c|}
\hline Variable Code & Expenditure Category \\
\hline 00 & All Consumer Goods \\
\hline 011 & Food \\
\hline 012 & Non-alcoholic beverages \\
\hline 021 & Alcoholic beverages \\
\hline 022 & Tobacco \\
\hline 031 & Clothing \\
\hline 032 & Footwear \\
\hline 041 & Actual rentals of housing \\
\hline 042 & Imputed rentals of housing \\
\hline 043 & Maintenance and repair of the dwelling \\
\hline 044 & Water supply and misc. services \\
\hline 045 & Electricity, gas and other fuels \\
\hline 051 & $\begin{array}{l}\text { Furniture and furnishings, carpets and other floor } \\
\text { coverings }\end{array}$ \\
\hline 052 & Household textiles \\
\hline 053 & Household appliances \\
\hline 054 & Glassware, tableware and household utensils \\
\hline 055 & Tools and equipment for house and garden \\
\hline 056 & Goods and services for routine household maintenance \\
\hline 061 & Medical products, appliances and equipment \\
\hline 062 & Out-patient services \\
\hline 063 & Hospital services \\
\hline 071 & Purchase of vehicles \\
\hline 072 & Operation of personal transport and equipment \\
\hline 073 & Transport services \\
\hline 081 & Postal services \\
\hline 082 & Telephone and telefax services and equipment \\
\hline 09 & Recreation and culture \\
\hline 10 & Education \\
\hline 111 & Catering services \\
\hline 112 & Accommodation services \\
\hline 12 & Misc. goods and services \\
\hline
\end{tabular}


Table A.2: List of EU Countries and Their Abbreviations

\begin{tabular}{|c|l|c|l|}
\hline Abbreviation & Country & Abbreviation & Country \\
\hline BE & Belgium & IT & Italy \\
\hline BG & Bulgaria & LT & Lithuania \\
\hline CY & Cyprus & LU & Luxembourg \\
\hline CZ & Czech Republic & LV & Latvia \\
\hline DE & Germany & MT & Malta \\
\hline DK & Denmark & PL & Poland \\
\hline EE & Estonia & PT & Portugal \\
\hline EL & Greece & RO & Romania \\
\hline ES & Spain & SE & Sweden \\
\hline FI & Finland & SI & Slovenia \\
\hline FR & France & UK & Slovakia \\
\hline HU & Hungary & & \\
\hline IE & Ireland & & \\
\hline & & & \\
\hline & & & \\
\hline
\end{tabular}

\section{Harmonised Index of Consumer Price Data}

While preparing the HICP data, we encountered two main challenges. First, as it was mentioned in the previous section, there are missing country-year price observations after constructing 30 expenditure categories. We therefore imputed missing country-year observations as follows:

- 3-digit category "Hospital Services" (063) data is missing for Slovenia in 2001; it is proxied using Slovenia' s 2002 price.

- 3-digit category "Hospital Services" (063) data is missing for Estonia between 2001 and 2003; these data are proxied using Estonia' s 2004 price.

- 3-digit category "Hospital Services" (063) data is missing for Hungary between 2001 and 2006; these data are proxied using Hungary's 2007 price.

- 3-digit category "Hospital Services" (063) data is missing for Slovakia and Romania between 2001 and 2015; they are proxied using the price of their 2-digit aggregate "Health" in the respective country and year. 
- 3-digit category "Telephone and Telefax Services and Equipment" (082) data is missing for Latvia in 2014; it is proxied using Latvia's 2013 price.

It is important to note that the fraction of proxied country-year price observations is a mere $0.002 \%$. Moreover, the mean expenditure fraction of main problematic 3-digit category "Hospital Services" (063) across countries is about $0.02 \%$. Therefore, we are confident that proxying missing price observations does not have a serious impact on our results.

A final challenge to deal with is the 3-digit category "Imputed Rentals of Housing" (042). Naturally, HICP does not provide any information on prices of this category. One immediate resolution for this problem would be proxying the prices of this category with prices of the 3-digit category "Actual Rentals of Housing” (041). However, by definition, values in "Imputed Rentals of Housing" (042) do not imply an actual expenditure; values purely represent the rental price of the dwelling as if it is consumed by its owner. Therefore, a price increase would not imply a decline in the real expenditure of the household who owns the dwelling. In order to neutralize the effect of this category, we assume that the price of "Imputed Rentals of Housing" (042) has not changed with respect to the base year. The fraction "Imputed Rentals of Housing" (042) in total expenditure across deciles is not large enough to explain away our findings. The table below, presents the fractions. For this reason, we believe, this assumption is not biasing our results.

Table A.3: Simple Mean of "Imputed Rentals of Housing" by Decile Across All 25 Countries

\begin{tabular}{|c|c|c|c|c|c|c|c|c|c|c|}
\hline Decile & 1 & 2 & 3 & 4 & 5 & 6 & 7 & 8 & 9 & 10 \\
\hline Share & $13.4 \%$ & $14.5 \%$ & $15.2 \%$ & $15.7 \%$ & $15.5 \%$ & $15.6 \%$ & $15.5 \%$ & $15.3 \%$ & $14.8 \%$ & $12.7 \%$ \\
\hline
\end{tabular}




\section{Appendix B}

\section{A Simple Model Using Stone-Geary Preferences}

We construct a simple model based on the stylized fact that poorer households spend a higher fraction of their income on necessities than on luxuries. Moreover, we provide a simple intuition for this fact. Following that logic, the model implies that richer households can more easily substitute away certain goods in response to price increases.

Consider a representative household with a Stone-Geary utility function in an economy which consists of two goods: necessities $\left(q_{n}\right)$ and luxuries $\left(q_{l}\right)$. The household maximizes

$$
U=\beta_{n} \ln \left(q_{n}-\gamma_{n}\right)+\beta_{l} \ln \left(q_{l}\right)
$$

over $q_{n}$ and $q_{l}$ such that the budget constraint $p_{n} q_{n}+q_{l}=y$ is satisfied. In this specification, $\gamma_{n}$ indicates the subsistence parameter of necessities (subsistence parameter of luxuries is assumed to be zero). Let $p_{n}$ be the price of necessities relative to luxuries and $y$ is the nominal income of the household. Finally, $\beta_{n}$ and $\beta_{l}$ are preference parameters. We assume $\beta_{n}>0, \beta_{l}>0$ and $\beta_{n}+\beta_{l}=1$.

Typical FOCs yield the following demand functions:

$$
\begin{gathered}
q_{n}^{*}=\gamma_{n}+\frac{\beta_{n}}{p_{n}}\left(y-p_{n} \gamma_{n}\right) \\
q_{l}^{*}=\beta_{l}\left(y-p_{n} \gamma_{n}\right)
\end{gathered}
$$

These demand functions are simple and intuitive. A household first sets aside enough income to purchase a subsistence level of necessities, then allocates the rest of its income, depending on prices and preference parameters. Following this, we derive the optimal expenditure share of necessities in total demand. 


$$
s_{n}^{*}=\frac{\left[\gamma_{n} p_{n}+\beta_{n}\left(y-p_{n} \gamma_{n}\right)\right]}{\left[\gamma_{n} p_{n}+\beta_{n}\left(y-p_{n} \gamma_{n}\right)\right]+\beta_{l}\left(y-p_{n} \gamma_{n}\right) p_{l}}
$$

Given $\beta_{l}>0$, an increase in income causes a higher increase in denominator due to higher scaling factor $\left(\beta_{n}+\beta_{l}>\beta_{n}\right)$. Hence, $\frac{\partial s_{n}^{*}}{\partial y}<0$. Intuitively, each household has to spend on necessities at least as much as the subsistence level, which is a constant. As the subsistence level-income ratio decreases in income, richer households spend a lower fraction on necessities, given that luxury goods are at least marginally desirable $\left(\beta_{l}>0\right)$.

Another implication of the model is that richer households have a higher ability to substitute away certain goods in response to a price increase. Let the price elasticity of demand of necessities be as follows:

$$
\begin{aligned}
\epsilon_{n}=\frac{\partial q_{n}^{*} / q_{n}^{*}}{\partial p_{n} / p_{n}} & =\frac{\frac{\partial q_{n}^{*}}{\partial p_{n}}}{\frac{q_{n}^{*}}{p_{n}}}=\frac{-\beta_{n} y}{p_{n} \gamma_{n}+\beta_{n}\left(y-p_{n} \gamma_{n}\right)} \\
& =\frac{-\beta_{n} y}{p_{n} \gamma_{n}+\beta_{n} y-\beta_{n} p_{n} \gamma_{n}}
\end{aligned}
$$

Note that $\left|\epsilon_{n}\right|<1$. Hence, $\frac{\partial\left|\epsilon_{n}\right|}{\partial y}>0$, which means that the price elasticity of demand for necessities is increasing in income. The intuition behind this result is as simple as the previous one. The household can only substitute the expenditures that is left after setting aside the subsistence level. Given that poorer households are left with a lower amount after paying for the subsistence, their ability to substitute is lower compared to richer households. 


\section{Appendix $\mathrm{C}$}

\section{Effective Inflation Rates by Country}

Figure C.1: Effective Inflation Rates of Poorest and Richest Deciles over Time by Country
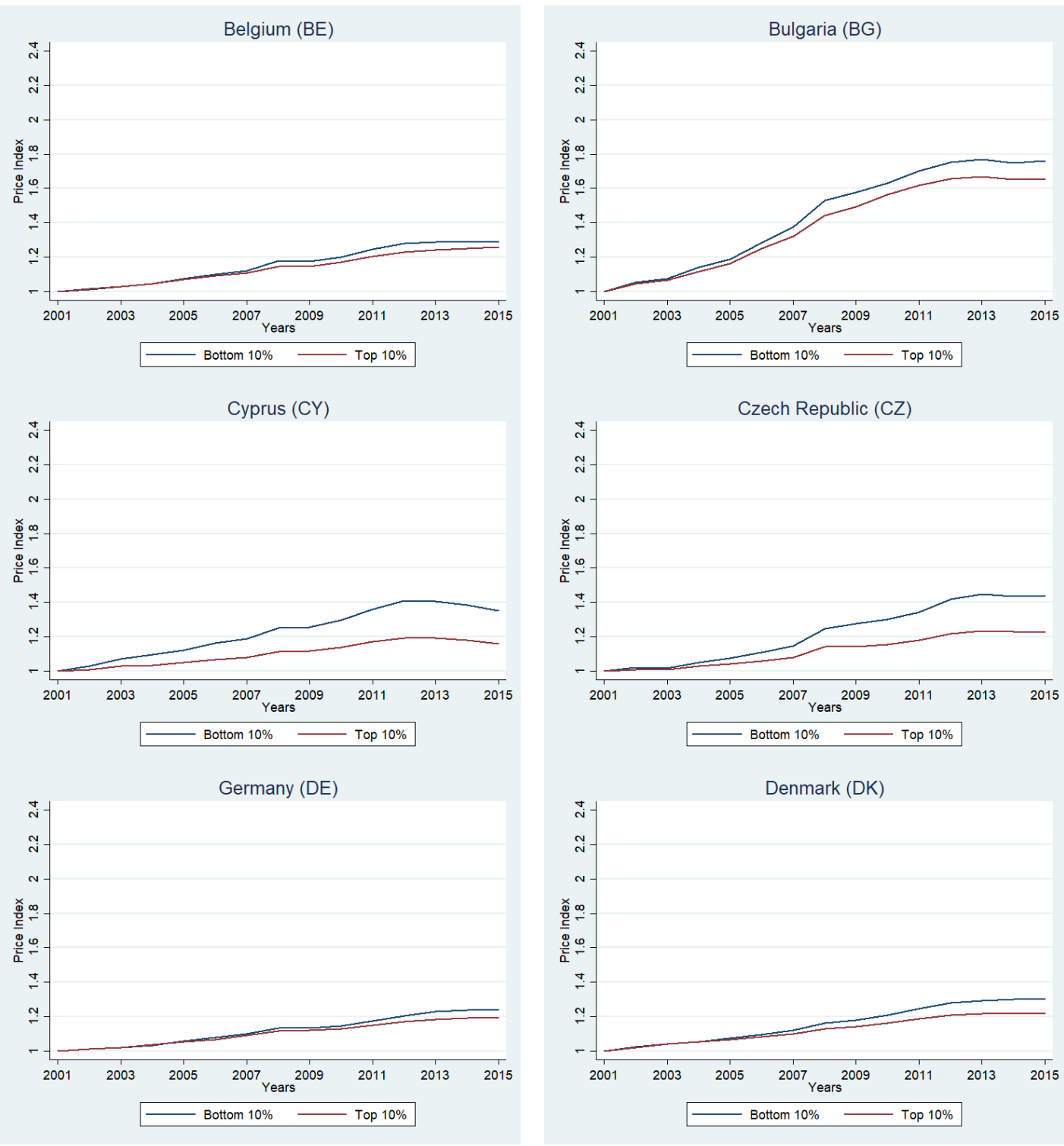

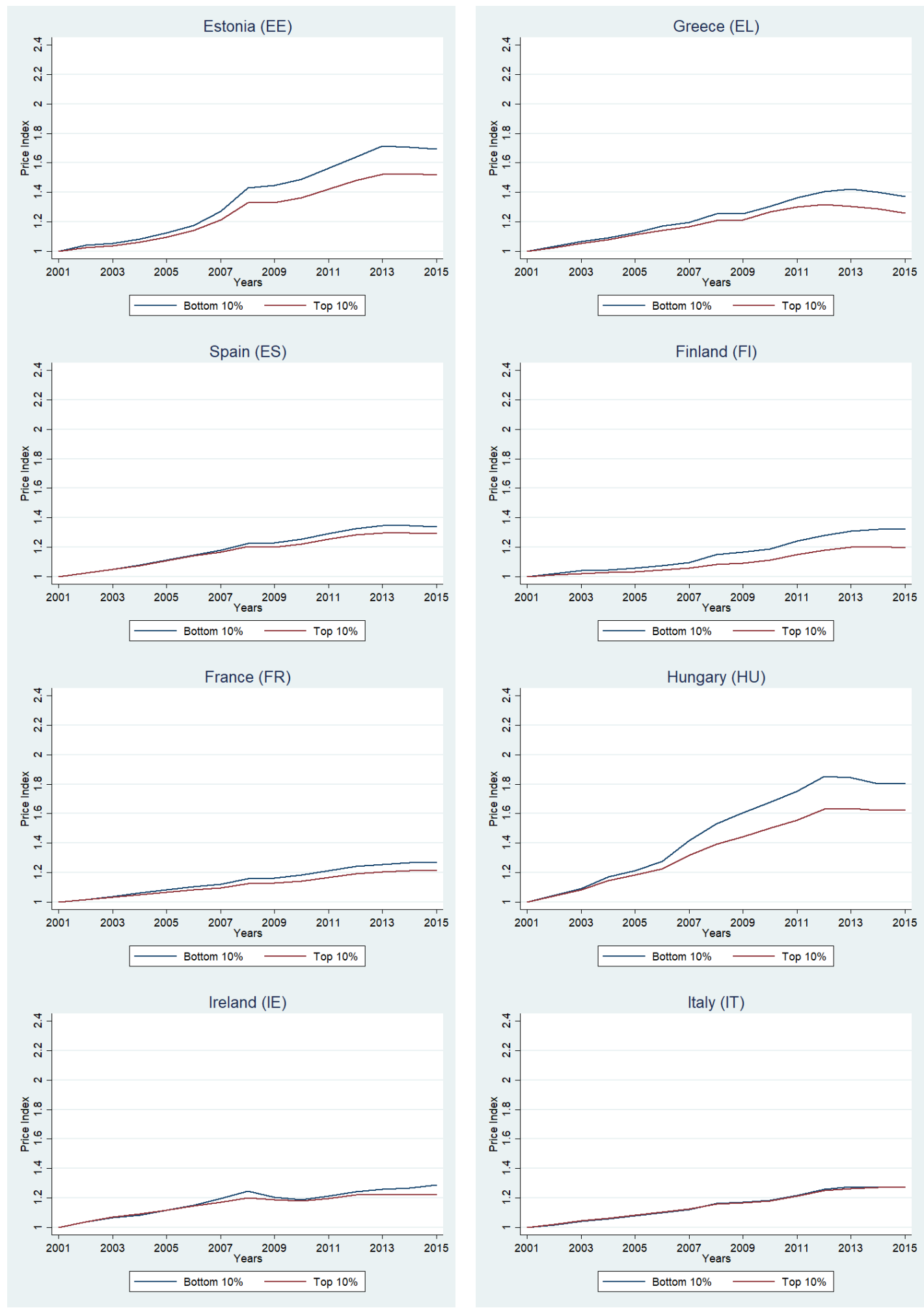

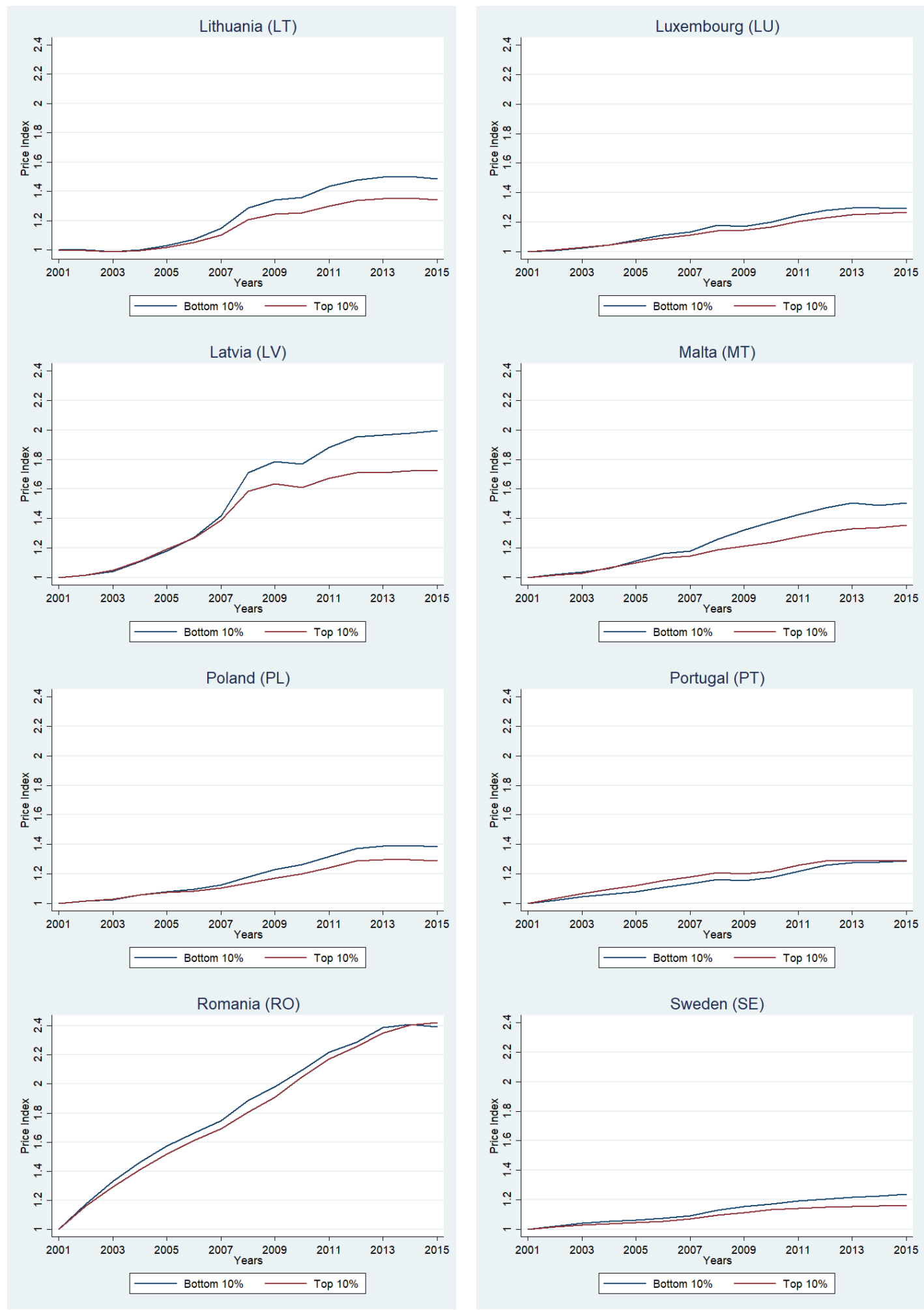

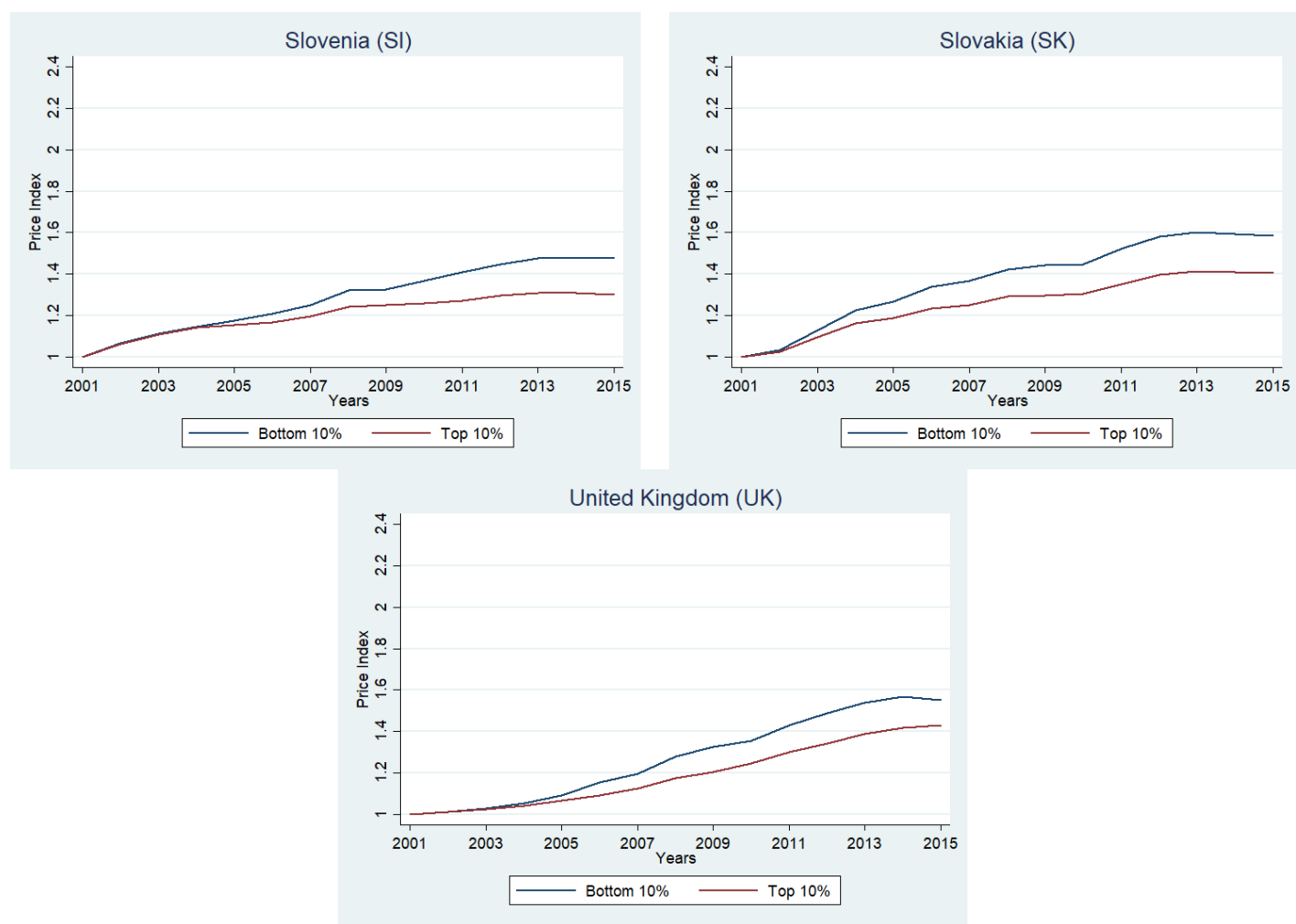


\section{Appendix D}

\section{Inequality Analysis}

Table D.1: Baseline Variance of Log Expenditure Measures by Country

\begin{tabular}{|c|c|c|c|c|}
\hline Country & $\begin{array}{l}\text { Variance of Log } \\
\text { Expenditure }\end{array}$ & Rank & $\begin{array}{c}\text { Adjusted Variance of } \\
\text { Log Expenditure }\end{array}$ & Rank \\
\hline Portugal & 0.371 & 1 & 0.370 & 3 \\
\hline Estonia & 0.369 & 2 & 0.419 & 1 \\
\hline Malta & 0.349 & 3 & 0.390 & 2 \\
\hline United Kingdom & 0.314 & 4 & 0.366 & 5 \\
\hline Latvia & 0.312 & 5 & 0.367 & 4 \\
\hline Italy & 0.303 & 6 & 0.303 & 9 \\
\hline Cyprus & 0.284 & 7 & 0.338 & 6 \\
\hline Lithuania & 0.282 & 8 & 0.322 & 7 \\
\hline Greece & 0.280 & 9 & 0.307 & 8 \\
\hline France & 0.273 & 10 & 0.289 & 11 \\
\hline Spain & 0.262 & 11 & 0.275 & 14 \\
\hline Finland & 0.261 & 12 & 0.295 & 10 \\
\hline Romania & 0.254 & 13 & 0.282 & 12 \\
\hline Luxembourg & 0.250 & 14 & 0.260 & 17 \\
\hline Poland & 0.243 & 15 & 0.266 & 15 \\
\hline Ireland & 0.238 & 16 & 0.263 & 16 \\
\hline Germany & 0.231 & 17 & 0.241 & 19 \\
\hline Bulgaria & 0.226 & 18 & 0.277 & 13 \\
\hline Belgium & 0.215 & 19 & 0.222 & 21 \\
\hline Slovenia & 0.206 & 20 & 0.243 & 18 \\
\hline Sweden & 0.198 & 21 & 0.215 & 22 \\
\hline Hungary & 0.196 & 22 & 0.231 & 20 \\
\hline Denmark & 0.168 & 23 & 0.181 & 23 \\
\hline Slovakia & 0.155 & 24 & 0.184 & 24 \\
\hline Czech Republic & 0.146 & 25 & 0.184 & 25 \\
\hline
\end{tabular}


Figure D.1: Absolute Change in Variance of Log Expenditure after applying Householdspecific Price Indices, 2001-15

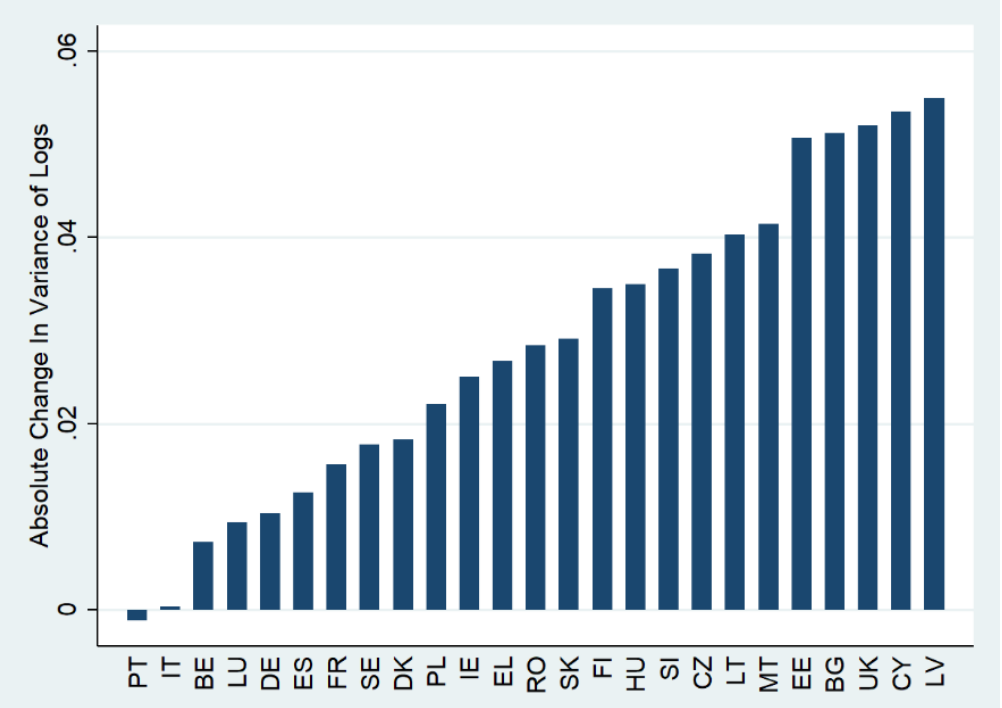

Figure D.2: Expenditure Share Differentials and Prices by Country, 2001-15
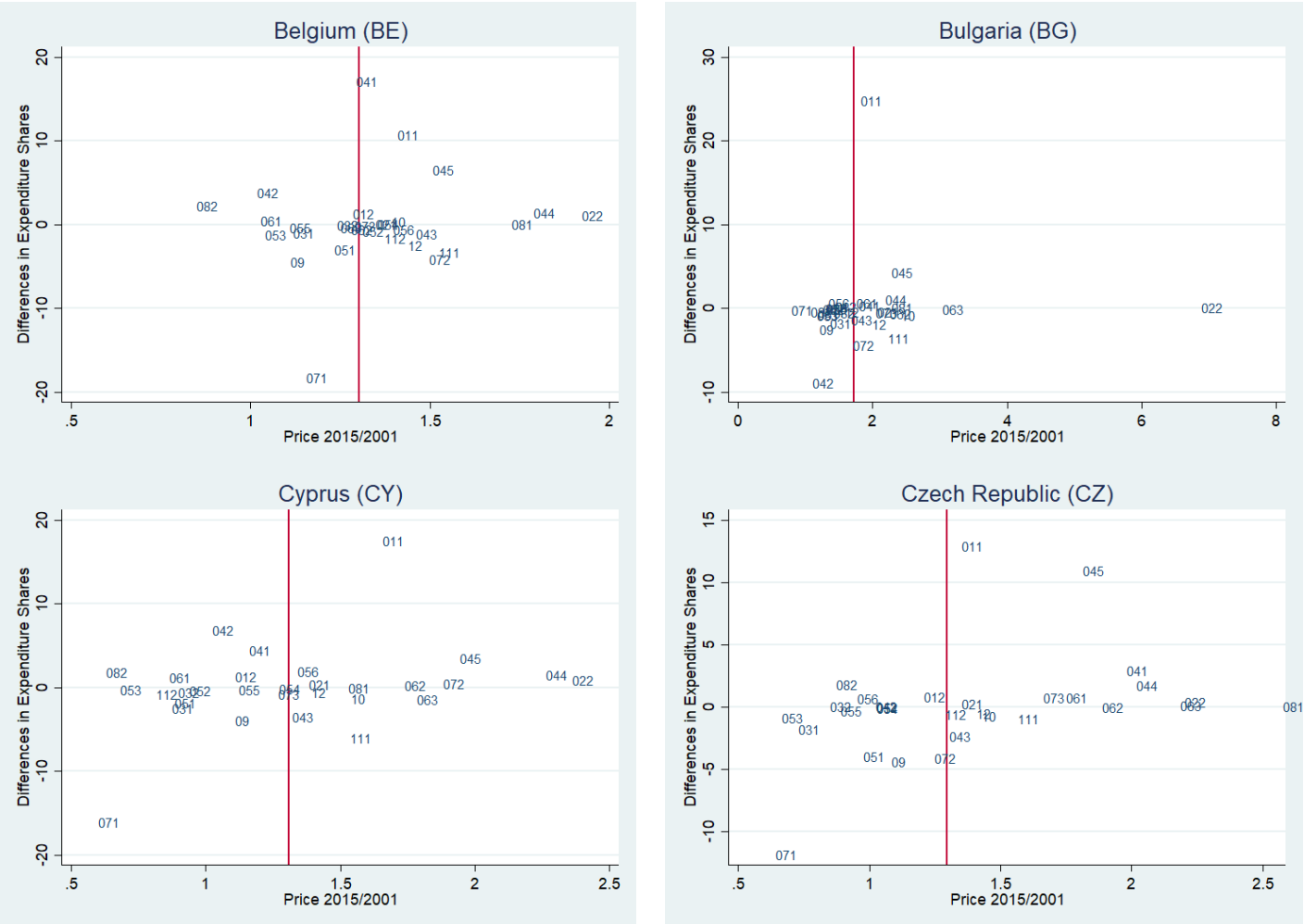

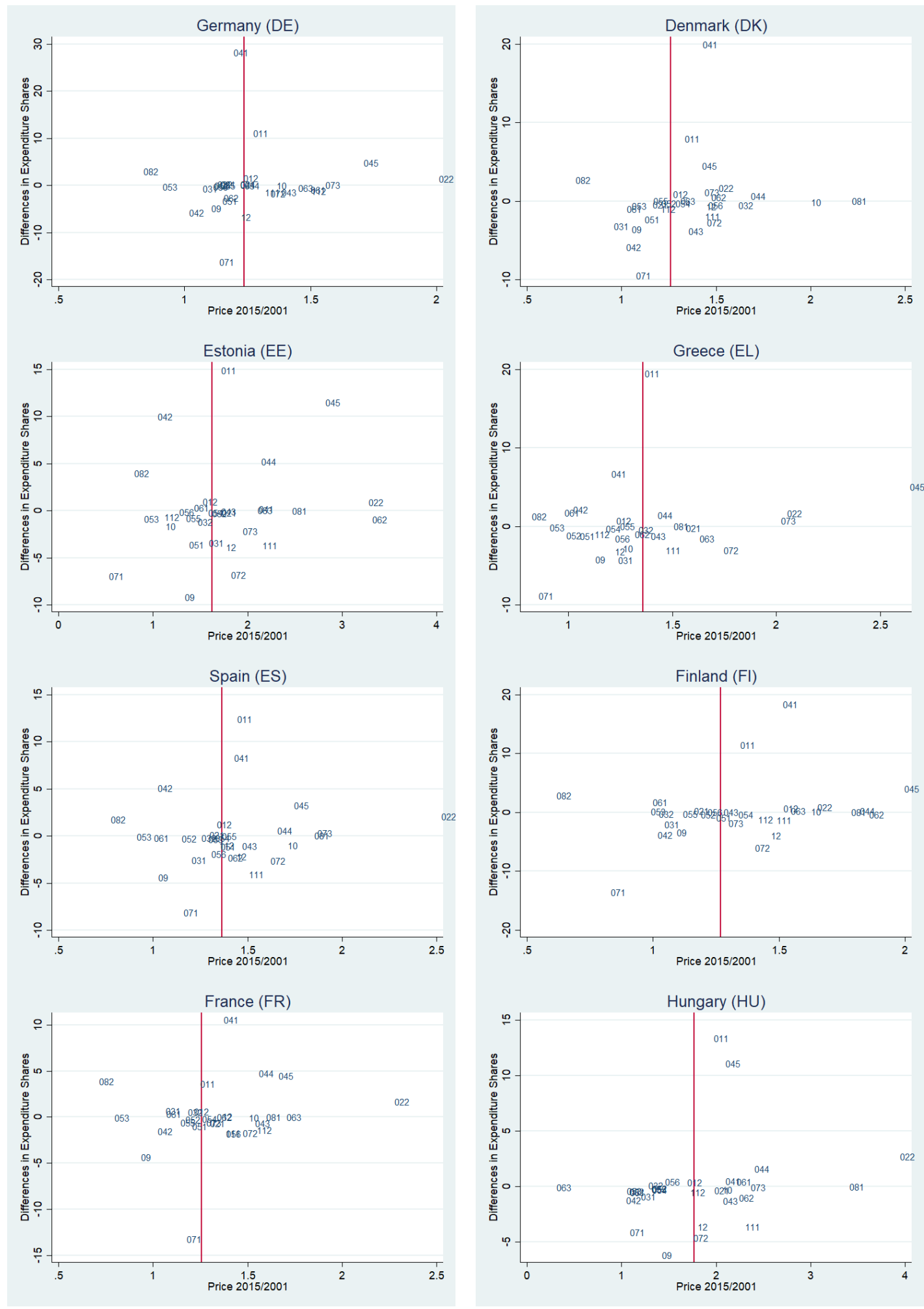

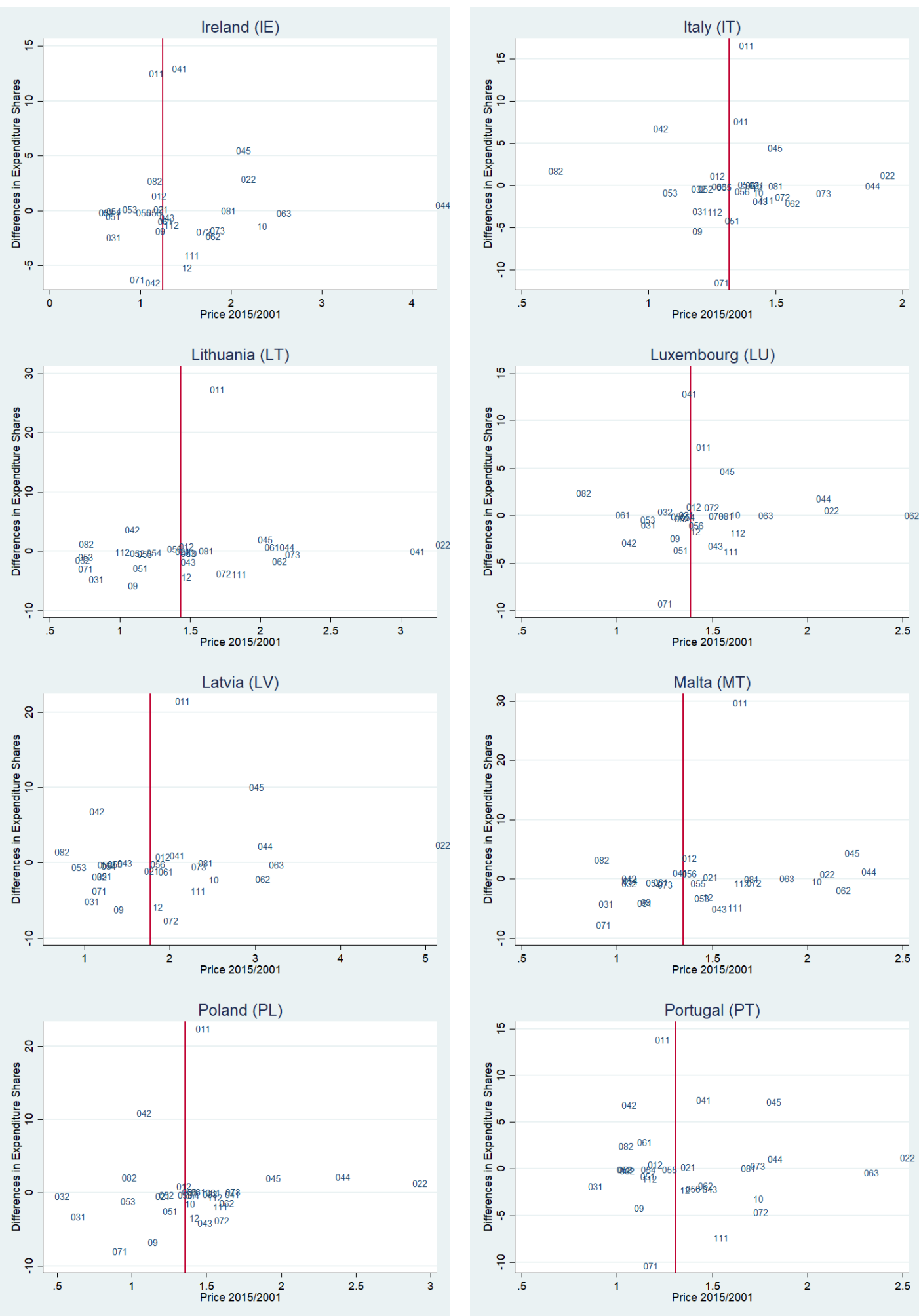

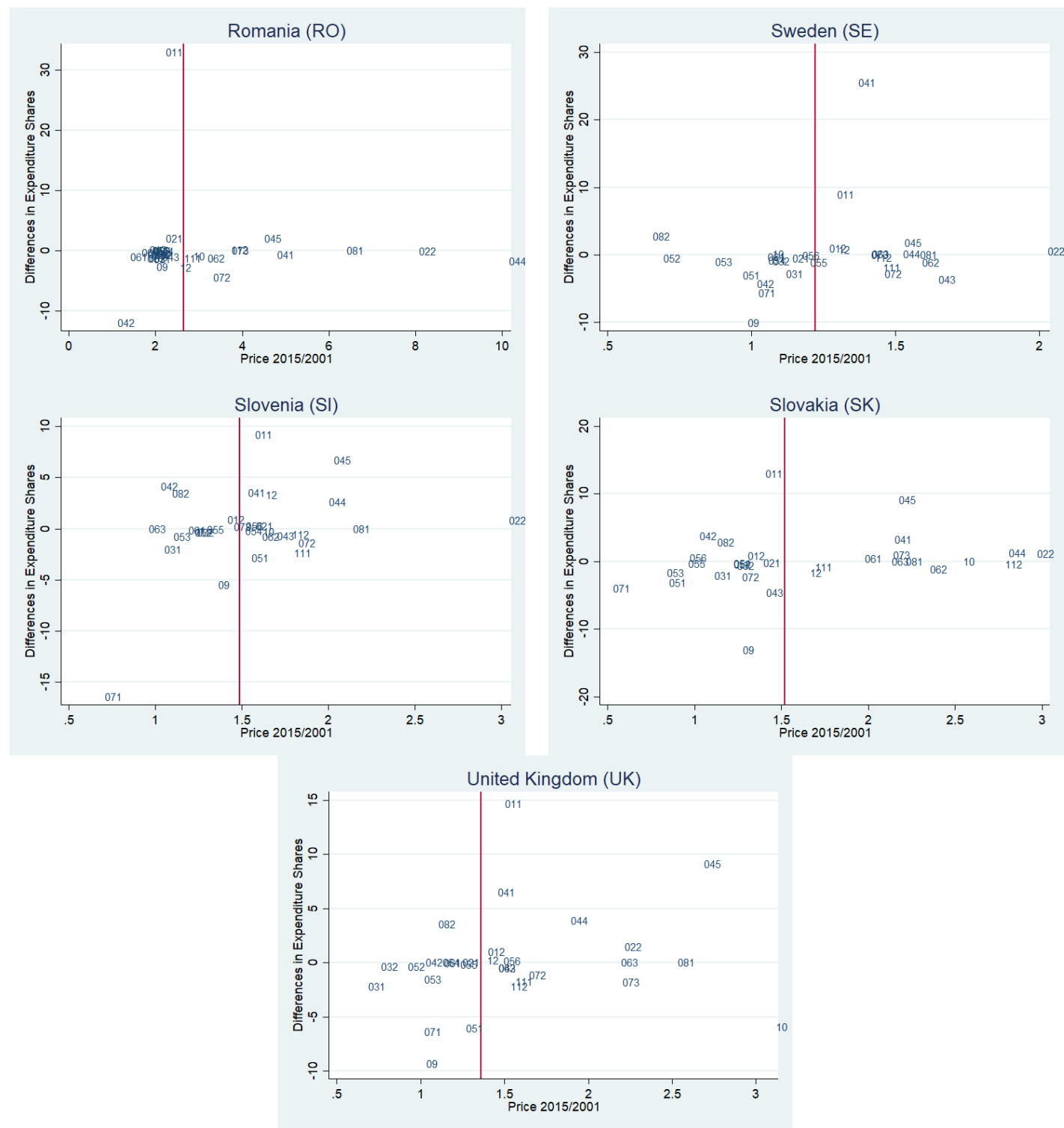

Notes: $Y$ - axis is the difference in the expenditure shares of the richest and the poorest decile. $X$-axis is the price of the corresponding category in 2015 divided by the 2001 price. Explanations of the category codes can be found in Appendix A (Table A.1). 


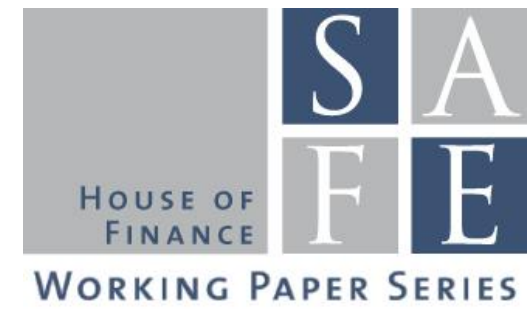

\section{Recent Issues}

No. 208 Roberto Casarin, Michele Costola, Erdem Yenerdag

No. 207 Claes Bäckman, Tobin Hanspal

No. 206 Loriana Pelizzon, Anjan Thakor, Calebe de Roure

No. 205 Horst Entorf, Jia Hou

No. 204 Loriana Pelizzon, Matteo

Sottocornola

No. 203 Florian Hett, Felix Schmidt

No. 202 Tobias H. Tröger

No. $201 \quad$ Dirk Krueger, Alexander Ludwig

No. 200 Nils Grevenbrock, Max Groneck, Alexander Ludwig, Alexander Zimper

No. 199 Tobias H. Tröger

No. 198 Henning Hesse, Boris Hofmann, James Weber

No. 197 Benjamin Clapham, Peter Gomber, Martin Haferkorn, Paul Jentsch, Sven Panz

No. 196 Benjamin Clapham, Peter Gomber, Sven Panz

No. 195 Benjamin Clapham, Peter Gomber, Martin Haferkorn, Sven Panz

No. 194 Baptiste Massenot
Financial Bridges and Network Communities

The Geography of Alternative Work

P2P Lending versus Banks: Cream Skimming or Bottom Fishing?

Financial Education for the Disadvantaged? A Review

The Impact of Monetary Policy Interventions on the Insurance Industry

Pushing Through or Slacking Off? Heterogeneity in the Reaction to Rank Feedback

Germany's Reluctance to Regulate Related Party Transactions

Optimal Taxes in the OLG Model with Uninsurable Idiosyncratic Income Risk

Cognition, Optimism and the Formation of Age-Dependent Survival Beliefs

Regulation of Crowdfunding in Germany

The Macroeconomic Effect of Asset

Purchases Revisited

Circuit Breakers - A Survey among International Trading Venues

Coordination of Circuit Breakers? Volume Migration and Volatility Spillover in Fragmented Markets

Managing Excess Volatility: Design and Effectiveness of Circuit Breakers

A Business Cycle Model with Neuroeconomic Foundations 